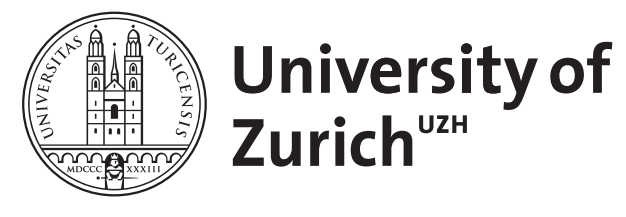

\title{
International price and earnings momentum
}

\author{
Leippold, Markus ; Lohre, Harald
}

\begin{abstract}
We find that price and earnings momentum are pervasive features of international equity markets even when controlling for data snooping biases. For European countries, we find that price momentum is subsumed by earnings momentum on an aggregate level. However, this rationale does not apply to each and every country. While the above explanation is confined to certain time periods in the U.S., earnings momentum nevertheless appears to be a crucial driver of the price momentum anomaly in many markets. Since we cannot establish a decent relation between momentum and macroeconomic risks, we suspect a behavioral-based explanation to be at work. In fact, we find momentum profits to be more pronounced for portfolios characterized by higher information uncertainty. Hence, the momentum anomaly may well be rationalized in a model of investors underreacting to fundamental news. Finally, we find that momentum works better when limited to stocks with high idiosyncratic risk or higher illiquidity, suggesting that limits to arbitrage deter rational investors from exploiting the anomaly.
\end{abstract}

DOI: https://doi.org/10.1080/1351847X.2011.628683

Posted at the Zurich Open Repository and Archive, University of Zurich

ZORA URL: https://doi.org/10.5167/uzh-55591

Journal Article

Accepted Version

Originally published at:

Leippold, Markus; Lohre, Harald (2012). International price and earnings momentum. European Journal of Finance, 18(6):535-573.

DOI: https://doi.org/10.1080/1351847X.2011.628683 


\title{
International Price and Earnings Momentum*
}

\author{
MARKUS LEIPPOLD ${ }^{\dagger}$ \\ University of Zurich \\ HARALD LOHRE ${ }^{\ddagger}$ \\ Deka Investment $\mathrm{GmbH}$
}

October 10, 2010

\footnotetext{
${ }^{*}$ We are grateful to Yakov Amihud, Frederick Barnard, Wolfgang Bessler, Markus Brechtmann, Andrea Buraschi, Lara Cathcart, Giulio Cifarelli, Michael Damm, Werner De Bondt, Allaudeen Hameed, Dieter Hess, Alexander Kempf, Joëlle Miffre, Thorsten Neumann, Theo Nijman, Christos Pantzalis, Bernd Scherer, James Sefton, Richard Stehle, Michael Wolf, Zaher Zantout, and the seminar participants at the 2008 CFS Research Conference on Asset Management and International Capital Markets in Frankfurt, the 2008 FMA European Conference in Prague, the 2008 EFMA Annual Meeting in Athens, the 3rd Conference on Advances in the Analysis of Hedge Fund Strategies at Imperial College, the Econometrics Seminar at the University of Zurich, the CFR Research Seminar at the University of Cologne, the 2008 London Quant Group Conference in Cambridge, and the INQUIRE Spring Seminar 2010 in Rome for helpful comments and suggestions. Note that this paper expresses the authors' views that do not have to coincide with those of Deka Investment. The authors gratefully acknowledge the financial support of INQUIRE Europe and the Swiss National Science Foundation (NCCR FINRISK).

${ }^{\dagger}$ Correspondence Information: University of Zurich, Swiss Banking Institute, Plattenstrasse 14, 8032 Zurich, Switzerland; leippold@isb.uzh.ch.

${ }^{\ddagger}$ Correspondence Information (Contact Author): Deka Investment GmbH, Mainzer Landstr. 16, 60325 Frankfurt/Main, Germany; harald.lohre@deka.de.
} 


\title{
International Price and Earnings Momentum
}

\begin{abstract}
We find that price and earnings momentum are pervasive features of international equity markets even when controlling for data snooping biases. For European countries, we find that price momentum is subsumed by earnings momentum on an aggregate level. However, this rationale does not apply to each and every country. While the above explanation is confined to certain time periods in the U.S., earnings momentum nevertheless appears to be a crucial driver of the price momentum anomaly in many markets. In fact, we find momentum profits to be more pronounced for portfolios characterized by higher information uncertainty. Hence, the momentum anomaly may well be rationalized in a model of investors underreacting to fundamental news. Finally, we find that momentum works better when limited to stocks with high idiosyncratic risk or higher illiquidity, suggesting that limits to arbitrage deter rational investors from exploiting the anomaly.
\end{abstract}

Keywords: Earnings Momentum, Price Momentum, Market Efficiency, Multiple Hypotheses Testing, Information Uncertainty, Liquidity

JEL Classification: G11; G12; G14; M40 
According to the Oxford Dictionary momentum is a force that is gained by movement. Price momentum entails the observation that past winning stocks continue to deliver superior returns in the short run while past losing stocks subsequently continue to disappoint. Likewise, earnings momentum refers to the observation of momentum in stock prices following the direction of analysts' earnings forecast revisions. Both phenomena have been documented for the U.S. by Jegadeesh and Titman (1993) and Chan, Jegadeesh, and Lakonishok (1996) in the early nineties. Moreover, Rouwenhorst (1998) and Griffin, Ji, and Martin (2003, 2005) evidence that the momentum effect carries over to many developed international markets in terms of magnitude and persistence.

Within this paper we confirm that price and earnings momentum are constantly defying capital market efficiency in international equity markets. Usually, this observation is being rationalized by either risk-based or behavioral-based explanations. However, such explanations are only meaningful if the momentum anomaly is not spurious in the first place. Especially, when a vast number of strategies is being tested around the globe, some strategies tested may excel by chance alone. Statistically speaking, there is a need to control for data snooping biases given the multitude of tests involved. While researchers have long been aware of data snooping biases, ${ }^{1}$ common statistical procedures are not always optimal in terms of power, and hence they are most likely to reject any given anomaly. However, we aim to detect as many countries as possible where the momentum anomaly actually exists. We therefore employ the recent proposal of Romano and Wolf (2005), which achieves improvements in power due to its stepwise nature and use of studentized test statistics. While Leippold and Lohre (2010a, 2010b) document that Sloan (1996)'s accrual anomaly and the dispersion effect of Diether, Malloy, and Scherbina (2002) are not robust to this battery of tests, we find that both price and earnings momentum are fairly persistent with regard to data snooping biases. Hence, the phenomenon is even more intriguing and the need for a sound economic explanation of the origins of momentum is apparent.

In examining the link between both momentum anomalies, we test the recent conjecture of Chordia and Shivakumar (2006) who claim that price momentum is merely a noisy proxy for earnings momentum in the U.S.. This explanation is intuitive, since price momentum may well be rationalized in a model of investors underreacting to fundamental news as represented by

\footnotetext{
${ }^{1}$ See Lo and MacKinlay (1990), Sullivan, Timmermann, and White (1999), and White (2000).
} 
earnings revisions. Along this line of reasoning, we check whether this explanation constitutes a broad pattern in a large sample of 16 European countries. Our findings are as follows. First, while we replicate the result of Chordia and Shivakumar (2006), the conjectured pattern has recently become more subtle. During the market frenzy at the end of the nineties, we observe a decoupling of price and earnings momentum in the U.S., which suggests that this period may be dominated by investors' over- instead of underreaction. Second, considering an aggregate European momentum strategy, we find that European price momentum appears to be a manifestation of earnings momentum throughout the whole twenty-year sample period. Third, while we cannot replicate this argument in all European countries, there is considerable evidence that earnings momentum is a crucial determinant in explaining price momentum for most countries.

Having established a link between both anomalies, we are still in need of a deeper rationale for the momentum effect. In further examining the international momentum phenomena, we fail to establish momentum as a proxy for macroeconomic risk. Rather supporting a behavioralbased argument, we find momentum strategies to be most profitable when restricted to winner and loser portfolios characterized by proxies of high information uncertainty. In other words, the noisier the fundamental information, the slower its incorporation into prices, which is in accordance with underreaction of investors.

Regardless of the origins of momentum, be it risk or behavioral biases, it is most puzzling why the anomaly is not arbitraged away. While various market anomalies are found to falter following their publication, see Schwert (2003), momentum does not. To explain this observation, Korajczyk and Sadka (2004) and Lesmond, Schill, and Zhou (2004) detect trading costs to be the single most important impediment to successfully implement momentum strategies in the U.S.. The amount of trading costs is not only driven by the huge turnover but also by liquidity risk. Hence, Chordia, Goyal, Sadka, Sadka, and Shivakumar (2009) accordingly find the post-earningsannouncement drift to be confined to illiquid securities. Even more so, Liu (2006) constructs a liquidity-augmented asset pricing model that almost captures the abnormal returns of standard U.S. price momentum strategies. In a related vein, Arena, Haggard, and Yan (2008) resolve this puzzle for the U.S. by showing that momentum profits are especially pronounced for stocks with high idiosyncratic volatility which suggests that the momentum phenomenon persists, since any arbitrageur wishing to exploit the anomaly is limited by high arbitrage costs. In substantiating 
this claim, we provide additional evidence that international momentum strategies appear to be mostly limited to highly illiquid stocks.

The paper's structure is as follows. In Section 1, we review prior evidence on the momentum anomalies both in the U.S. and in European markets. Section 2 presents the data we use for our study. In Section 3, we establish the traditional analysis of momentum anomalies in European equity markets. In Section 4, we subject both anomalies to recent methods of multiple testing. Section 5 examines the interplay of both anomalies. Section 6 further explores the link of momentum to the macroeconomy and its interaction with information uncertainty and liquidity. Section 7 concludes.

\section{Review of Momentum Strategies}

\subsection{Price Momentum}

Momentum in individual stock prices has first been documented by Jegadeesh and Titman (1993) and their approach of quantifying price momentum has become the industry standard. They consider a portfolio that is long in the winner decile and short in the loser decile. These decile portfolios arise from several winner and loser portfolios based on overlapping time periods. The stocks are ranked monthly according to their performance over the last six months and assigned accordingly to the respective decile portfolios. These are held for six months. Hence, the winner or loser decile of the associated price momentum strategy of a given month is made up of six portfolios. Jegadeesh and Titman (1993) find such a price momentum strategy to earn more than $1 \%$ above the risk-free rate per month. Even though the decile portfolios usually consist of smaller sized companies with high beta risk, the associated hedge strategy's return cannot be fully explained by significant size or market exposure. The fact that the momentum anomaly is not arbitraged away and still persists is even more intriguing, see Jegadeesh and Titman (2001).

In explaining the phenomenon of U.S. price momentum, Jegadeesh and Titman (2001) examine post-holding period return patterns of momentum portfolios. These patterns favor a behavioral explanation of momentum to be triggered from market participants' under- or overreaction to new information. Overreaction will drive stock prices to levels that are not fundamentally 
justified, giving rise to a subsequent reversion back to their initial level. On the other hand, given limited information processing capabilities, investors may underreact to news which may positively effect a company's fundamental value. Since overconfidence likely causes investors to cling to their original views, this fundamental news may only gradually transmit into the company's stock price. In this case, one obtains a flat post-holding period return of a momentum strategy.

Not only is the price momentum anomaly confined to the U.S., it has also been documented in several international studies, such as in Rouwenhorst (1998) for Europe and more recently in Griffin, Ji, and Martin (2003, 2005) for a large set of countries. While Rouwenhorst (1999) finds emerging markets to exhibit price momentum, Bekaert, Erb, Harvey, and Viskanta (1997) contend that momentum in these markets are less consistently profitable.

\subsection{Earnings Momentum}

Ball and Brown (1968) have first documented the phenomenon of post-earnings announcement drift which encompasses the tendency of stock prices to drift in the direction suggested by recent earnings surprises. This observation is most likely driven by investors of bounded rationality failing to fully appreciate the earnings information, which results in a delayed price response, see Bernard and Thomas (1989). While studies on the post-earnings announcement drift rely on some measure of realized earnings surprise, one may also resort to analysts' earnings forecasts as a more direct measure of earnings expectations. Doing so provides a more timely measure, given that non-U.S. companies usually report earnings on an annual basis as opposed to quarterly reporting. The investment strategy building on the above metric is typically referred to as earnings momentum.

The implementation of the earnings momentum strategy is similar to the one of price momentum. However, companies are not being ranked dependent on the level of prior returns but prior earnings revisions. As in Chan, Jegadeesh, and Lakonishok (1996), we build a moving average of cumulated revisions over the prior six months to capture the change in earnings expectations:

$$
R E V 6_{i t}=\sum_{j=0}^{6} \frac{f_{i t-j}-f_{i t-j-1}}{p_{i t-j-1}}
$$


where $f_{i t}$ is the consensus estimate in month $t$ of the $i$-th company's earnings for the current fiscal year, as provided by the Institutional Brokers' Estimate System (I/B/E/S). The resulting difference, the monthly revision, is then scaled by the prior month's stock price. We go long in the highest earnings revisions quintile and short in the lowest quintile in any given month according to the value of $R E V 6_{i t}$. Given a holding period of six months the resulting hedge strategy's long leg consists of six overlapping portfolios, as does the short leg.

\subsection{Linking Price and Earnings Momentum}

It is straightforward to speculate as to whether price and earnings momentum may reflect the very same mispricing or behavioral bias. In fact, prior studies like Chan, Jegadeesh, and Lakonishok (1996) find that the U.S. momentum effect is concentrated around subsequent earnings announcements and show that price momentum may partially be explained by underreaction to earnings information. However, they contend that price momentum is not subsumed by earnings momentum, since each ranking variable has some incremental predictive power for future returns. This view is shared by Griffin, Ji, and Martin (2005), who analyze both momentum strategies in an international context. Given that Hong and Swaminathan (2003) only detect price momentum in countries that also exhibit earnings momentum nevertheless makes the case for a closer relation of the two anomalies. Indeed, Chordia and Shivakumar (2006) show that U.S. price momentum appears to be a manifestation of earnings momentum for the period from 1972 to 1999.

\section{Data}

\subsection{Sample Selection}

We use a comprehensive sample of companies domiciled in 17 equity markets, 16 European markets and the U.S., covering the period from January 1988 to March 2009. All data has been gathered from Datastream including I/B/E/S earnings revisions data.

Table 1 contains information on the sample countries classified by region. We collect companies for each country by merging the live and dead research lists provided by Datastream 
and thereby obtain a total number of 65,925 companies. To arrive at our final sample, we have pruned the initial country research lists as follows. First, we adjust each country list for secondary issues and cross-country listings to prevent double-counting. In particular, we extract 30,552 companies. Hence, only one half of the initial list does refer to major listings. Second, we screen for non-equity issues, i.e., we exclude investment trusts, ADRs, and the like. Third, we also exclude OTC stocks and stocks that are only listed on regional exchanges. Following these two screens, we are left with 16,662 companies. We further exclude those having market capitalization below 10 million USD, which leaves us with a final sample of 13,291 companies. Almost one half are U.S. companies and the biggest five markets comprise some $80 \%$. To avoid survivorship bias, the sample includes 4,550 "dead" companies, i.e., one third of the whole sample, ranging from $16.9 \%$ for Greece to $52.2 \%$ for Portugal. The label "dead" applies to companies in extreme distress and to those being merged, delisted, or converted.

Since we aim to investigate price and earnings momentum strategies, we additionally check the coverage of return and earnings revisions data. Unsurprisingly, the coverage for return data is close to $100 \%$ in each country, on average $98.4 \%$ of the companies do exhibit at least one return observation over the course of the sample period. As for the earnings estimates, these figures are more fragmentary. However, the average coverage still amounts to $75.5 \%$ spanning a range from $62.6 \%$ (Belgium) to $94.1 \%$ (Spain). Note that our sample contains a certain amount of penny stocks that will not be included in the momentum strategies. We do not discard them right away, since being a penny stock is not a static firm characteristic. In particular, we do not invest in companies with stock price below $5 \$$ at the beginning of a given month.

\subsection{Return Data}

We consider monthly stock returns in local currency inclusive of dividends by employing total return figures. To represent the respective markets, we choose broad market indices as compiled by Datastream and 3-month-T-bills serve as a proxy for the risk-free rate.

Ince and Porter (2006) show that the price momentum effect cannot be detected in the U.S. when naïvely using raw Datastream data, an observation that appears to extend to other international markets as well, see Lohre (2008). For curing these data issues, Ince and Porter 
(2006) propose two major adjustments. One is to remove non-common equity from the respective country research lists and the other is to screen for irregular return patterns. Since the former has already been dealt with when deleting secondary issues, we merely have to address the quality of return data. We follow Ince and Porter (2006) in adjusting the return data to allow for reasonable statistical and economic inferences.

Interestingly, we find our comprehensive sample to be hardly confounded by erroneous return data. For instance, the U.S. only requires to change 161 return observations which represents $0.01 \%$ of all observations. This fraction is even smaller for Europe for which we adjust 69 observations across all 16 countries. We assume that Datastream has significantly corrected the database in response to the objections of Ince and Porter (2006). ${ }^{2}$ Still, the remaining issues might severely affect statistical inferences and weeding them out renders us even more comfortable with the quality of data.

\section{Detecting Price and Earnings Momentum}

\subsection{Risk and Return}

We next report descriptive statistics of momentum-based quintile portfolios by country. In computing momentum portfolio returns, we follow the standard approach of Jegadeesh and Titman (1993) that stipulates the use of overlapping portfolios as described in the previous section. ${ }^{3}$ Tables 2 and 3 give average monthly buy-and-hold return and volatility figures together with two risk proxies, size and beta.

First, we assess the profitability of the price momentum hedge strategy by considering the return differential along with its $t$-statistic. For the U.S., we obtain a monthly hedge return of 72 basis points at a monthly volatility of $3.9 \%$ giving rise to a $t$-statistic of 2.99 . The latter is even higher for the European hedge strategy providing a return of 111 basis points per month but at a lower volatility. Further, using the $t$-statistic metric, we identify 13 European countries

\footnotetext{
${ }^{2}$ In fact, according to an employee of Thomson Financial Services the return time series is constantly screened for possible glitches in the price, dividend, and adjustment factor history. In particular, the history of several U.S. OTC stocks has been fixed recently, which presumably accounted for a lot of issues detected by Ince and Porter (2006).

${ }^{3}$ Note that we are using quintile instead of decile portfolios.
} 
that have anomalous returns on a $5 \%$ level or better. If we relax the significance level to $10 \%$, Ireland and Sweden appear to be anomalous as well, leaving Portugal as the only country for which price momentum is not significant, albeit positive. All in all, we recover prior evidence of pronounced international momentum effects as documented by Rouwenhorst (1998) and Griffin, $\mathrm{Ji}$, and Martin (2003, 2005).

The loser quintile is likewise contributing to the return spread as the winner quintile. This finding confirms prior evidence that a long-only investor may well benefit from an according momentum strategy. However, the extreme quintile portfolios are the riskiest within all countries, since the winner and loser portfolios prove to be more volatile than the portfolios with less extreme price momentum. To judge a systematic risk bias of these portfolios, we compute betas according to the classical regression

$$
R_{i t}-R_{F t}=\alpha_{i}+\beta_{i}\left(R_{M t}-R_{F t}\right)+\varepsilon_{i t}
$$

where $R_{i t}$ denotes the return of quintile $i, R_{F t}$ is the risk-free rate and $R_{M t}$ is the market return of the respective country. For more than half of the countries, the extreme quintile portfolios exhibit high betas, while the remaining portfolios appear to be homogeneous in terms of beta. Moreover, in 16 countries we obtain the highest betas for the loser quintile. Also, there is a size bias for the two extreme quintile portfolios. When we examine size, measured in terms of the logarithm of market value, we find that the two extreme portfolios are mostly populated by smaller companies. Again, the bias is more severe in the loser quintile, which may in turn explain its conspicuous market exposure. Concerning the price momentum strategy, we usually observe betas that are slightly negative suggesting that one may partially hedge against downside moves of the market.

Regarding earnings momentum, the U.S. strategy earns 46 basis points per month at a volatility that is almost half the size of the price momentum volatility. Thus, the according t-statistic of 3.12 is similar. On the other hand, the European earnings momentum strategy exhibits improved risk-adjusted performance with a return of 76 basis points per month at $1.65 \%$ volatility, giving a $t$-statistic of 7.42. Across Europe, Tables 2 and 3 give rise to 15 significant return differentials while the remaining countries also show positive differentials. 
However, there is no general pattern of price momentum outperforming earnings momentum in terms of return at the cost of higher volatility. Both, price and earnings momentum strategies are rather volatile and risk-mitigating effects with regard to market volatility do only occur in some countries. Compared to price momentum, these earnings momentum differentials seem to be driven less often by the short leg. This is a a comforting result since the earnings momentum losers are seriously more volatile than the winners. Even though the long leg has a severe size bias it exhibits less extreme beta exposure than the short leg of the earnings momentum strategy. Also, the earnings momentum strategy exhibits negative betas that are usually smaller in absolute terms than those of the according price momentum strategy.

[Fig. 1 about here.]

In the upper graphs of Figure 1, we plot the cumulative returns of the winner and loser quintiles of the earnings and price momentum strategies together with the evolution of an equallyweighted market portfolio. Inspecting the cumulative wealth of the extreme quintiles for the U.S., we support the findings of Chordia and Shivakumar (2006), namely that price and earnings momentum are closely related. For both price and earnings momentum, the respective winner portfolios move almost in sync. However, the price momentum losers underperform the earnings momentum losers In addition, the loser portfolio stays well below the market portfolio and the winner portfolio stays well above it. We observe slightly different behavior in Europe. Both legs of the price momentum strategy seem to be closely related to the earnings momentum counterparts, however, they are shifted upwards.

Also, inspecting the cumulative momentum returns for the U.S. and Europe over time in the lower graphs of Figure 1 confirms the above statements. Both, price and earnings momentum, seem to be closely tied. Over the nineties, the respective return paths nearly coincide. However, the earnings momentum strategy is smoother. While this observation has already been apparent from the descriptive statistics, we additionally learn that the higher volatility figures mainly arise over an extended but limited period following the burst of the technology bubble in 1999. Hence, though usually sailing in safe waters, a price momentum investor may experience very turbulent times with volatility well in excess of common market levels. Of course, the most recent financial crises also represents a very challenging environment for momentum investors that have suffered 
from rather devastating returns, especially in March 2009, which is the last observation in our sample period.

\subsection{Time-Series Regressions}

Since most of the hedge strategies are highly volatile, we wonder whether their high returns are solely compensating for risk. To further examine the performance of our strategies, we therefore check if the long-short portfolio returns can be attributed to common risk factors. We adopt the standard approach of Fama and French (1993) and estimate a regression model of the form

$$
R_{L t}-R_{S t}=\alpha+\beta\left(R_{M t}-R_{F t}\right)+\gamma R_{S M B t}+\delta R_{H M L t}+\varepsilon_{t},
$$

where $R_{L t}-R_{S t}$ is the return difference of the respective hedge strategy, i.e., the long leg minus the short leg. For each country we compute country-specific factors as follows. A country's broad market index represents its market return $R_{M t}$, while the size and value factor, $R_{S M B t}$ and $R_{H M L t}$, are computed according to the methodology of Fama and French (1993). Given the factor structure in (3), we can identify the alpha generated by the hedge strategy net of common risk factors.

Table 4 displays the results of a Fama-French regression for price momentum according to equation (3) that uses 255 monthly returns spanning the period from January 1988 to March 2009. Across all countries, the risk factors explain most of the variation of the loser and winner quintiles' excess returns, thus confirming our descriptive analysis in the previous section. However, concerning the long-short strategies, we note that the model's explanatory power is generally low, confirming prior evidence as in Fama and French (1996). The resulting alphas are positive and significant at the 5\%-level for 16 out of 17 countries, with Ireland being the odd one out. Note that the hedge strategies are also promising in terms of economical significance since they generate monthly alphas in excess of 67 basis points, the Norwegian alpha even amounts to 136 basis points, followed by 127 basis points for Italy and for Greece. Across countries, we note that the alphas are mostly driven equally by the long and the short leg, with a slight tendency towards the short leg. However, the U.S. alpha of 83 basis points is almost entirely due to the short leg. 
Table 5 gives the analogous results of the Fama-French regression for earnings momentum which is not captured by common risk factors as well. All countries exhibit positive alphas that are significant on a 5\%-level in 16 cases - the exception to the rule are Greece and Italy. Hence, this analysis significantly hardens our pure return diagnostics. As for the sources to the earnings momentum alphas, there is also a tendency towards the short leg.

\section{Momentum Strategies and Data Snooping}

From the previous section we learn that 15 out of 17 countries exhibit positive and significant price momentum alphas and 16 exhibit positive and significant earnings momentum alphas. However, these alphas may be spurious, since they arise from single hypothesis tests performed for each country. Therefore, we will subject both momentum strategies to recent econometric methods that additionally account for multiple testing. These testing procedures either control the familywise error rate (FWE) or the false discovery proportion (FDP). Below, we will briefly introduce the concept behind these methods. ${ }^{4}$

\subsection{Accounting for Multiple Testing}

When simultaneously testing several, say $S$, trading strategies against a common benchmark, some strategies may outperform others by chance alone. For instance, extensive re-use of a given database or testing one investment idea on various markets of similar nature are prime examples. The latter case applies to our setting, since we wish to detect anomalies in several equity markets simultaneously. Our tests in the previous section suggest a momentum anomaly for a specific country, if the respective alpha is statistically proven positive "beyond any reasonable doubt". Hence, there is a small chance that a wrongly identified anomaly passes the test. However, this logic assumes that only one country is tested. If many countries are tested at the same time, it may become more likely that some countries' momentum will be wrongly identified as anomalies. Therefore, we must carefully combine the individual hypotheses into multiple testing procedures that control for the possibility of data snooping biases.

\footnotetext{
${ }^{4}$ For an overview, see Lehmann and Romano (2005, Chapter 9).
} 


\subsubsection{Methods Based on the FWE}

The traditional way to account for multiple testing is to control the familywise error rate, defined as the probability of rejecting at least one of the true null hypotheses. If this objective is achieved, one can be confident that all hypotheses that have been rejected are indeed false (instead of some true ones having been rejected by chance alone). There are many methods that control the FWE, the simplest one being the well-known Bonferroni (1936) method, which consists of a plain $p$-value adjustment, i.e., the initial significance level $\alpha$ is divided by the number of hypotheses under test. Evidently, this method is strict and would result in an outright rejection of any momentum anomaly in all countries. However, it is also important to use a method that provides as much power as possible so that false hypotheses have a chance of being detected.

Romano and Wolf (2005) note that the conservativeness of classical procedures like the one of Bonferroni (1936) is due to the fact that these methods assume a worst-case dependence structure of the test statistics. For instance, if we consider the extreme case of all hedge strategies yielding the very same alpha, then individual tests should be carried out at the level $\alpha$, which obviously is more powerful than the Bonferroni (1936) method. Hence, accounting for the true dependence structure is important. In our set-up, we would like to detect as many countries as possible in which the momentum anomaly actually exists. In this respect, the recent proposal of Romano and Wolf (2005) appears to be the state of the art. On the one hand, it improves upon Bonferronitype methods based on the individual $p$-values by incorporating the dependence structure across test statistics. On the other hand, it improves upon the bootstrap reality check of White (2000) by incorporating a stepwise approach and by employing studentized test statistics. We briefly describe this $k$-StepM method in Appendix A, which ultimately returns a confidence region for the return or the alpha.

\subsubsection{Method Based on the False Discovery Proportion (FDP)}

When the number of hypotheses under test is very large, the error control may be based on the false discovery proportion rather than on the familywise error rate. Let $F$ be the number of false rejections arising from a multiple testing method and let $R$ be the total number of rejections. We define the FDP as the fraction $F / R$, given that $R>0$. Otherwise, the FDP is zero. A 
multiple testing method controls the FDP at level $\alpha$ if $P(\mathrm{FDP}>\gamma) \leq \alpha$, for any $P$, at least asymptotically. Typical values of $\gamma$ are 0.05 and 0.1 .

Romano, Shaikh, and Wolf (2008) present a generalized version of the StepM method that allows for controlling the FDP, the FDP-StepM ${ }_{\gamma}$ method. The method is somewhat complex and the reader is referred to the paper for the details. However, the first step of the method is easy to understand and works as follows. Consider controlling the FDP with $\gamma=0.1$. The method starts with applying the StepM method. If less than nine hypotheses are rejected, the method stops. If nine or more hypotheses are rejected, the method continues and some further hypotheses might be rejected subsequently.

Romano, Shaikh, and Wolf (2008) compare the $k$-StepM methods to competing methods by means of a simulation study and two empirical applications. They find that all of the methods provide control of the respective error rates. However, the FWE control is too strict, but generalized error rates such as the $k$-FWE or the FDP allow for more power. Also, the StepM methods turn out to be more powerful than those methods that do not account for the dependence structure of test statistics. Therefore, the methods related to StepM are most suitable for our purpose.

\subsection{Is Momentum Due to Data Snooping?}

Reconciling the results of the traditional analysis, we are left with 17 positive and significant price momentum alphas and 16 positive and significant earnings momentum alphas. Since this result could have occurred by chance alone, we need to account for multiple testing issues using the methods presented above.

To control the FWE, we consider the $k$-StepM method for $k=1$ which is the appropriate choice given the number of strategies under study. To control the FDP, we pursue the FDP$\operatorname{StepM}_{\gamma}$ using $\gamma=0.1$. We keep the significance level constant at $5 \%$ across all multiple testing procedures and we present results for the return of the hedge strategies as well as their alphas arising from the Fama-French time series regressions. To account for potential serial correlation in the return series, we use a kernel variance estimator based on the Parzen kernel to studentize the test statistics, see Andrews (1991). The bootstrap method is the stationary bootstrap with 
an average block size of 12 months. ${ }^{5}$

Panel A of Table 6 reports the countries' return statistics for price momentum. We provide the lower confidence band $c_{l}$ for the returns using studentized test statistics according to the StepM and FDP-StepM ${ }_{\gamma}$ method, respectively. Since we are in a one-sided test setting, we give the lower limits of the confidence interval as computed in the last step of the respective method. The value in the column labeled $r e j$ equals 1 if $0 \notin\left[c_{l}, \infty\right)$, which indicates the rejection of capital market efficiency and suggests the presence of an anomaly in the respective country.

Concerning the results for the price momentum returns, we observe 14 rejections by the StepM method. Thus, the FDP-StepM ${ }_{\gamma}$ is not equivalent to the StepM, since the number of rejections exceeds nine. Moreover, the FDP-StepM $\mathrm{F}_{\gamma}$ rejects market efficiency for all countries.

Panel B of Table 6 displays the multiple testing results using the Fama-French price momentum alphas as test statistics. With this metric, price momentum is found to be overwhelmingly robust to data snooping. Already the StepM method yields 18 rejections of capital market efficiency, hence, this result is echoed by the FDP-StepM ${ }_{\gamma}$.

As for the earnings momentum strategies, Table 6 reveals results that are qualitatively similar to the ones obtained for price momentum. However, considering returns as test statistic, the StepM gives only ten rejections of capital market efficiency as does the FDP-StepM $\mathrm{F}_{\gamma}$ method. Considering alphas as test statistic, the StepM method detects 15 and the FDP-StepM $_{\gamma}$ method 17 significant alphas.

In closing this section, we conclude that the detected price and earnings momentum anomalies are confirmed by our battery of tests that account for multiple testing issues. By and large, both phenomena prove to be quite persistent and raise the need of sound economic inference.

\section{Linking Price and Earnings Momentum}

Having ruled out data snooping biases as possible explanations to the momentum effects, we will further delve into the economic nature of these phenomena. In fact, one may wonder whether both price and earnings momentum may be traced back to similar sources, be it a behavioral bias

\footnotetext{
${ }^{5}$ Using the stationary bootstrap with an average block size of six months leaves results virtually unchanged.
} 
or a compensation for risk. When inspecting the cumulative returns in Figure 1, we have already noted that price and earnings momentum do follow very similar return paths. To quantify this similarity, one may simply compute the correlation of selected price and earnings momentum portfolios. In untabulated results we document that portfolios with identical price and earnings momentum ranking unsurprisingly exhibit correlation figures ranging from 0.8 to 0.95 . Moreover, this relation also holds in the remaining countries with the same order of magnitude. ${ }^{6}$

Given these results, we suspect the price and earnings momentum hedge strategies to be positively correlated as well. Indeed, while Greece unsurprisingly exhibits rather zero correlation, all of the remaining time series of returns exhibit significantly positive correlation with correlation coefficients between 0.262 and 0.632 . Among the 17 countries, we find 15 (nine) with correlation in excess of $0.3(0.4)$. We also compute the correlation of price and earnings momentum alphas using the respective time-series arising from the trailing Fama-French regressions of Section 3. While the Danish alphas' correlation is not distinguishable from zero the general pattern of alpha correlations is consistent with the return correlations, giving 15 significant figures ranging from 0.138 (Sweden) to 0.749 (Germany). Among the 17 countries we find 13 (11) with correlations inexcess of $0.3(0.4)$. Hence, the unsystematic component of price and earnings momentum returns is highly correlated as well.

\subsection{Does Earnings Momentum Subsume Price Momentum?}

So far we have compiled considerable evidence that price and earnings momentum are closely connected in the U.S. and several European markets. In fact, Chordia and Shivakumar (2006) show that the U.S. price momentum alpha vanishes when additionally controlling for earnings momentum, while the U.S. earnings momentum alpha is robust when vice versa controlling for price momentum. Chordia and Shivakumar (2006) thus reason that price momentum is just a noisy proxy for earnings momentum. While this reasoning is quite persuasive, we wonder whether this observation carries over to other markets. Therefore, when testing for price momentum, we extend the Fama-French setting of Equation (3) to a four-factor model by adding an earnings

\footnotetext{
${ }^{6}$ These results are available upon request.
} 
momentum factor:

$$
R_{L t}-R_{S t}=\alpha+\beta\left(R_{M t}-R_{F t}\right)+\gamma R_{S M B t}+\delta R_{H M L t}+\zeta R_{P M N t}+\varepsilon_{t},
$$

where $R_{P M N t}$ refers to the returns of the earnings momentum strategy (positive minus negative earnings revisions). Accordingly, Table 7 contrasts the Fama-French results to those of the above four-factor model for all countries' respective hedge strategies. For the U.S. and the aggregate European strategy, we additionally give the results for the quintile portfolios. While the returns of the quintile portfolios are usually reasonably captured by the Fama-French factors, the returns of the price momentum strategies are not. Even though these strategies sometimes have loadings to one common factor or another, the adjusted $R^{2}$ s are typically quite low with the U.S. exhibiting the largest $R^{2}$ of $19.7 \%$.

Considering the alphas of quintile portfolios, we note a monotonic increase from loser to winner portfolios. For instance, the monthly U.S. price momentum alpha of 83 basis points results from -77 basis points for the loser quintile and to +5 basis points from the winner quintile. However, this huge spread is almost eroded when controlling for the earnings momentum factor. The loser quintile's alpha is -47 basis points and the winner quintile's alpha reduces to -18 basis points. As a consequence, the U.S. price momentum ceases to be significant under the four-factor model, consistent with the results of Chordia and Shivakumar (2006).

The general pattern in Europe is similar. For instance, for the European strategy we observe the following. While the Fama-French model attains an adjusted $R^{2}$ of $12.5 \%$, the four-factor model explains $40.3 \%$ of the variation in European price momentum returns, cutting down the Fama-French alpha of 123 basis points to insignificant 24 basis points. Across all countries, the addition of the earnings momentum strategy in (4) seems reasonable, since all portfolios except for Italy exhibit significant loadings to this factor. In particular, the adjusted $R^{2}$ of the hedge strategies usually increases by a considerable amount. In this sense, all countries' price momentum alphas are clearly reduced in the four-factor model and so are the corresponding $t$-statistics. The latter reductions imply statistical insignificance in six out of 16 European countries. The price momentum alphas of Austria, Finland, Ireland, Netherlands, Portugal, and Sweden are subsumed by the respective earnings momentum factor. 
According to Chordia and Shivakumar (2006), for earnings momentum to be the crucial driver of price momentum, the former should be robust when controlling for the latter. Hence, we determine the earnings momentum alphas arising from the following four-factor model

$$
R_{L t}-R_{S t}=\alpha+\beta\left(R_{M t}-R_{F t}\right)+\gamma R_{S M B t}+\delta R_{H M L t}+\eta R_{W M L t}+\varepsilon_{t},
$$

where the original Fama-French model is augmented by the return of the price momentum strategy, $R_{W M L t}$ (winner minus loser). In Table 8 we contrast the Fama-French results to those of the above four-factor model for all countries' respective hedge strategies. As before, results for the quintile portfolios according to the U.S. and the European aggregate strategy are also depicted. Again, we note that the additional factor leads to a considerable increase in statistical fit. In fact, the adjusted $R^{2}$ of the Fama-French model and the four-factor model almost resemble the figures obtained in the price momentum case. Consistent with Chordia and Shivakumar (2006), the U.S. earnings momentum alpha remains large at 44 basis points with a highly significant $t$-statistic of 3.73. Given that the European earnings momentum alpha has a $t$-statistic of 6.15 , we suspect that this observation carries over to other countries. Indeed, 10 of 14 original European anomalies remain significant after controlling for price momentum. Only Austria, Norway, Spain, and Switzerland do cease to have significant earnings momentum alphas.

To summarize, among 17 countries we initially find 16 countries exhibiting significant price momentum alphas in a classical Fama-French setting - Greece exhibits neither price nor earnings momentum. Further excluding Ireland who does not exhibit price momentum we are left with 14 countries of which five follow the explanation offered by Chordia and Shivakumar (2006), i.e., earnings momentum subsumes price momentum. These countries include the U.S., Finland, the Netherlands, Portugal, and Sweden. Among the eight remaining four-factor price momentum anomalies, five countries also have four-factor earnings momentum anomalies (Denmark, France, Germany, and the U.K.). Two countries' earnings momentum alphas cease to be significant (Austria and Norway) and Spain and Switzerland have no significant four-factor alphas at all. In summary, we obtain an aggregate European pattern that suggests a translation of Chordia and Shivakumar (2006)'s argument to European equity markets which is less accentuated on a 
country-level.

To uncover whether this reasoning may be confined to special circumstances, we investigate the time series of price momentum alphas arising from a trailing Fama-French regressions according to equation (3). We use a 36-month window and plot the resulting alphas in the upper graphs of Figure 2 for earnings momentum and in the lower graphs of Figure 2 for price momentum. Merely focussing on Fama-French alphas (dashed lines) both momentum strategies' alphas prove to be consistently positive throughout the sample period. However, while the evolution of price momentum alphas is rather volatile, earnings momentum alphas behave more steadily. Interestingly, the momentum strategies have experienced severe drawdowns at the end of the nineties which they seem to have recovered from within a quite short time span. However, while the European strategies keep up their level the U.S. strategies' alphas seem to have faded away.

First, we consider earnings momentum and contrast the respective Fama-French alpha (dashed line) and the four-factor alpha (solid line) in the upper graphs of Figure 2. While the four-factor earnings momentum alphas are slightly reduced as compared to figures arising from the FamaFrench setting, we observe that earnings momentum is still very prominent in both regions, however, the European strategy is less volatile than the U.S. one. Turning to price momentum we see that the large U.S. Fama-French alpha is substantially reduced when additionally controlling for earnings momentum. However, by the end of 1999, which coincides with the end of the sample period in Chordia and Shivakumar (2006), this relation breaks down for some years. Obviously, price and earnings momentum have decoupled following the burst of the tech bubble. This reasoning supports the general view that earnings momentum typically will be a result of investors' underreaction to fundamental news, while the market frenzy at the end of the nineties is more likely the result from overreaction. In addition, our finding suggests that U.S. investors will most likely have put less weight on earnings information following several accounting scandals at the beginning of the century. On the other hand, the European FamaFrench price momentum alpha is literally neutralized by the earnings momentum factor for the whole sample period. On the other hand Hence, while earnings momentum is a crucial driver of price momentum, there seem to be other forces at work, too.

[Fig. 2 about here.] 


\section{Origins of Momentum: Risk or Behavioral Bias?}

The results of the previous section essentially suggest that any momentum rationale will be closely linked to the drivers of earnings momentum and is rather due to a behavioral bias. In further rationalizing the momentum anomaly, we will analyze the interaction of momentum with measures of information uncertainty and we will investigate the role of liquidity risk in momentum profits.

\subsection{Momentum and Information Uncertainty}

The theoretical model of Hong and Stein (1999) posits that firm-specific information only gradually spreads across investors resulting in underreaction and, as a consequence, short-term return continuation. If momentum is due to investors' underreaction to fundamental news, the respective price drift should be higher in more opaque information environments for which information diffusion is slowest. In fact, Hong, Lim, and Stein (2000) find empirical support for their theory by demonstrating that U.S. momentum strategies are more effective in companies of small size or in companies with low analyst coverage. Besides these two metrics, Zhang (2006) recently provides evidence that the U.S. price momentum strategy is also more effective when limited to high uncertainty stocks as measured by firm age, dispersion in analysts' earnings forecasts, stock volatility, and cash flow volatility. Especially, the dispersion in analysts' earnings forecasts has been used in prior studies to proxy for differences in opinion, see Diether, Malloy, and Scherbina (2002). For instance, this heterogeneity in beliefs is a necessary condition for price drift in the model of Banerjee, Kaniel, and Kremer (2009), a link that is empirically corroborated for the U.S. by Verardo (2009).

Of course, establishing a link between international momentum and information uncertainty would further substantiate the momentum rationale of investors underreacting to fundamental news. Hence, we will examine price and earnings momentum profits for different degrees of information uncertainty. We consider four measures to proxy for information uncertainty: Analyst coverage, size, total stock volatility, and idiosyncratic volatility. Idiosyncratic volatility arises from a standard Fama-French regression and total stock volatility is estimated using stock returns. For both volatilities, we use return data over the last three years. 
Table 9 gives the results for the price momentum strategy in the upper panel A. In particular, we first sort stocks into five quintiles based on past returns. For each quintile the stocks are further sorted into three terciles based on one of the four information uncertainty proxies. Obviously, this procedure requires a sufficient number of companies in a given country to deliver meaningful results. Therefore, we exclude the seven smallest countries from the analysis, i.e., Austria, Belgium, Finland, Greece, Ireland, Norway, and Portugal.

Our findings are as follows. First, we find U.S. price momentum to be indeed more pronounced for stocks with low analyst coverage or smaller size. However, across volatility terciles, be it total or idiosyncratic volatility, the price momentum returns are more uniform. Second, these findings do not only translate to the aggregate European momentum strategy, but also to most of the European country strategies. In fact, only Denmark does refute the underreaction rationale. Third, while the earnings momentum results are quite similar among the major equity markets, we note that the results for some smaller countries are somewhat muted.

Thus, having gathered substantial support for the underreaction theory, one may wonder as to why the momentum anomaly is not arbitraged away. Recent research for the U.S. contends that high arbitrage costs prevent rational investors from exploiting the momentum anomaly. ${ }^{7}$ Presumably, the cost of short-selling small stocks is not offset by the expected momentum profits. The fact that we often find momentum to be most pronounced in stocks with high idiosyncratic volatility, which is a common proxy for arbitrage costs, constitutes persuasive explanation for the persistence of the momentum effect.

\subsection{Momentum and Liquidity}

In further elaborating on the above argument, we next examine the role of liquidity when implementing momentum strategies. Lesmond, Schill, and Zhou (2004) and Korajczyk and Sadka (2004) evidence that exploiting U.S. price momentum is costly. In fact, trading costs appear to erode all of the potential profits rendering the momentum arbitrage opportunity an illusion. The trading costs basically derive from frequent trading in mostly illiquid stocks. Consequently, Sadka (2006) documents a close relation between liquidity risk and U.S. momentum strategies.

\footnotetext{
${ }^{7}$ See Arena, Haggard, and Yan (2008) for price momentum and Mendenhall (2004) for the post-earnings announcement drift.
} 
Moreover, Liu (2006)'s liquidity-augmented two-factor asset pricing model almost completely subsumes the U.S. price momentum alpha. Hence, we expect liquidity to also play a crucial role in inhibiting profitable execution of the European momentum strategies.

To operationalize this conjecture, we analyze the profitability of the momentum strategies when restricting to winner and loser stocks characterized by different degrees of liquidity. Liu (2006) aptly describes liquidity "as the ability to trade large quantities quickly at low cost with little price impact." To account for the according distinct dimensions of liquidity, we compute different liquidity metrics. A stock's dollar volume or its turnover allow to capture the trading quantity dimension. As for the price impact dimension, we resort to the ILLIQ measure of Amihud (2002), which is the absolute daily return divided by the associated dollar volume. To obtain an aggregate monthly value of $I L L I Q$, we simply compute its mean over the corresponding daily values. The fourth measure is the one introduced by Liu (2006), which has been designed to capture multiple dimensions of liquidity such as trading speed and trading quantity. Its definition is as follows:

$$
\text { Liu Measure }=\text { Number of No-Trading Days over the prior } 12 \text { months }+\frac{1 / \text { Turnover }}{1,000,000},
$$

where turnover is the average daily turnover over the prior 12 months. This measure addresses the trading speed dimension of liquidity, since it very well captures lock-in-risk, i.e., the danger of being locked in a certain position that cannot be sold. ${ }^{8}$

Table 10 displays the profitability of momentum strategies restricted to winner and loser stocks characterized by different degrees of liquidity. In particular, we first sort stocks into five quintiles based on past returns or earnings revisions. For each quintile the stocks are further sorted into three terciles based on one of the four liquidity measures. Again, we exclude the seven smallest countries from the analysis, i.e., Austria, Belgium, Finland, Greece, Ireland, Norway, and Portugal. Panel A of Table 10 gives the results for the price momentum strategy. Across most countries and liquidity metrics, the general pattern is that the least momentum profits occur for the most liquid stocks and that profitability is increasing with illiquidity. For instance, U.S. price momentum for stocks with the highest dollar volume is only significant at

\footnotetext{
${ }^{8}$ Note that while the first three measures only take into account the stock's liquidity over the precedent month, the Liu measure hinges on data of the preceding year.
} 
the $10 \%$-level.

However, this pattern of momentum profitability decreasing with liquidity is less pronounced for the aggregate European strategy. In addition, the according hedge returns still amount to at least 96 basis points per month with $t$-statistics well above four, which suggests that momentum may be less costly to implement in Europe than in the U.S.. Our finding on the European aggregate seems to be driven by the U.K., Germany, Italy, and Switzerland, in which price momentum is rather strong among more liquid securities. On the other hand, the Netherlands do not exhibit sustainable momentum in the most liquid securities. However, Spain and Denmark even reverse the expected outcome by exhibiting no price momentum in the least liquid securities and Sweden is hardly showing any evidence of price momentum at all.

Interestingly, when using the share turnover as liquidity metric, the relation between liquidity and momentum profitability is sometimes reversed. For instance, judging liquidity by share turnover, both the U.S. and European aggregate price momentum strategy are most profitable in the most liquid securities. This puzzling result is in line with Hou, Peng, and Xiong (2006), who argue that trading volume as measured by turnover is a proxy for investor attention. When price momentum is mainly an overreaction-driven phenomenon, it should be relatively stronger among high turnover stocks. Vice versa, earnings momentum that is likely to be more related to underreaction should be relatively stronger among low turnover stocks, since investor attention is presumably lower.

The evidence in Panel B of Table 10 does recover such an argument for U.S. momentum strategies to some extent. While U.S. price momentum is profitable among high turnover stocks, earnings momentum is only generating an insignificant return of 16 basis points among high turnover stocks, corroborating the rationale of Hou, Peng, and Xiong (2006). However, for European stocks, we cannot draw the same conclusion. In many countries countries and the European aggregate, the high turnover stocks generate significant returns often larger than those for low turnover stocks. Nevertheless, given the temporary decoupling of price and earnings momentum after the burst of the tech bubble reported in Figure 2, such a result has been expected. Therefore, we conclude that there are times at which overreaction may play a significant role in driving a wedge between price and earnings momentum strategies. As for the U.S. earnings 
momentum strategy, we further find that the liquidity effect is most pronounced for the $I L L I Q$ measure in Panel B of Table 10. We obtain an insignificant monthly return spread of 25 basis points. Hence, we complement the findings of Chordia, Goyal, Sadka, Sadka, and Shivakumar (2009), who show the post-earnings announcement drift to be equally useless among illiquid stocks as measured by $I L L I Q$. Interestingly, our findings on earnings momentum profits for the aggregate Europe sample are quite different. Across all liquidity measures, the strategy earns at least 65 basis points with $t$-statistics between four and eight. However, the country-level results are more in line with the persuasive U.S. story. For example, Denmark, the Netherlands, Spain, and Sweden exhibit considerably less earnings momentum for highly liquid stocks. Finally, the overall grouping of the different country strategies into the different terciles (last two rows of Panel A and Panel B) suggests that liquidity appears to be a more severe impediment to implementing price momentum strategies as opposed to earnings momentum strategies.

\section{Conclusion}

The investigation of a given security mispricing typically addresses two questions. Is the anomaly simply a compensation for risk or is the anomaly real and, if yes, what behavioral bias is driving it? Of course, these questions are only meaningful if the security mispricing is not spurious in the first place. Hence, one needs to safeguard against data snooping biases. We find that both price and earnings momentum are robust with respect to multiple testing issues, reinforcing the growing body of research documenting magnitude and persistence of both anomalies. Researchers have long been speculating about a link between price and earnings momentum. Inspired by the work of Chordia and Shivakumar (2006), we find that European price momentum most likely is subsumed by earnings momentum. However, there are some European countries that do not support such a conclusion. As for the U.S., we especially observe some decoupling of price and earnings momentum following the burst of the tech bubble. In any case, our findings suggest that the price momentum rationale will most likely be related to earnings momentum and we thus narrow the search in favor of a behavioral-based explanation. In particular, winner and loser portfolios characterized by high information uncertainty give rise to even larger momentum profits. Thus, given that price momentum largely is earnings momentum in disguise, our 
evidence supports the rationale of momentum being driven by investors' underreaction to fundamental news. Moreover, we attribute the persistence of the momentum anomaly to the fact that significant arbitrage costs prevent investors from its exploitation. We find liquidity to be a crucial driver in governing the momentum effects. However, while the U.S. momentum effects clearly are most pronounced among illiquid winner and loser stocks, there are some European markets that exhibit very profitable momentum strategies even for highly liquid stocks. 


\section{Appendix A: Multiple Testing based on the StepM Method}

We describe the $k$-StepM that allows for controlling the $k$-FWE. Consider $S$ individual decision problems of the form

$$
H_{s}: \theta_{s} \leq 0 \text { versus } H_{s}^{\prime}: \theta_{s}>0, \quad 1 \leq s \leq S,
$$

each referring to the hedge strategy in country $s$. We define the parameter $\theta_{s}$ in such a way that under the null hypothesis $H_{s}$, strategy $s$ does not beat the zero benchmark. Given the time series of the hedge strategies, we can compute the test statistic $w_{T, s}$ with an estimate of its standard deviation $\sigma_{T, s}$ based on the returns and the strategies' alphas according to the Fama-French momentum regressions. In particular, using monthly hedge returns $x_{t, s}$, we compute average monthly buy-and-hold returns as in Section 3. Thus, we have

$$
w_{T, s}=\bar{x}_{T, s}=\frac{1}{T} \sum_{t=1}^{T} x_{t, s},
$$

which we studentize by $\sigma_{T, s}$ that we estimate using the Parzen kernel. Likewise, the test statistic for the alpha is the intercept from estimating equation (3)

$$
w_{T, s}=\hat{\alpha}_{T, s}
$$

studentized by the estimated standard deviation of $\hat{\alpha}_{T, s}$.

Within the $k$-StepM method, we first re-label strategies such that $r_{1}$ corresponds to the largest test statistic and $r_{S}$ to the smallest one. Then, we need to determine a confidence region of the form

$$
\left[w_{T, r_{1}}-\sigma_{T, r_{1}} d_{1}, \infty\right) \times \cdots \times\left[w_{T, r_{S}}-\sigma_{T, r_{S}} d_{1}, \infty\right)
$$

Whenever $0 \notin\left[w_{T, r_{s}}-\sigma_{T, r_{s}} d_{1}, \infty\right)$, we reject $H_{s}$ for $s=1, \ldots, S$. To control the FWE, $d_{1}$ ideally 
is given by the $(1-\alpha)$-quantile of the distribution of the largest 'centered' studentized ${ }^{9}$ statistic

$$
\frac{w_{T, s}-\theta_{s}}{\sigma_{T, s}}
$$

among all true hypotheses. However, we do not know which hypotheses are true and we do not know the true probability mechanism $P$. Therefore, we take the largest difference among all hypotheses and we replace $P$ by a bootstrap estimate $\hat{P}$, which implies that the StepM method will only allow for asymptotic control of the FWE. This feature is shared by all other commonly used multiple testing procedures.

If we suppose that we have rejected $R_{1}<k$ hypotheses, we can construct a new confidence region to reexamine the remaining $\left(S-R_{1}\right)$ smallest test statistics

$$
\left[w_{T, R_{1}+1}-\sigma_{T, R_{1}+1} d_{2}, \infty\right) \times \cdots \times\left[w_{T, r_{S}}-\sigma_{T, r_{S}} d_{2}, \infty\right)
$$

which is a smaller confidence region, because it typically holds that $d_{1}>d_{2}>\cdots>d_{S}$. Hence, we can reject more false hypotheses. Therefore, such a stepwise procedure is more powerful than the single-step method. For the computation of $d_{2}$, we again lack both $P$ and the set of true hypotheses. For $P$, we use the bootstrap estimate $\hat{P}$. However, we now only maximize over the set of hypotheses that have not been rejected yet. Since this is a smaller set, $S-R_{1}$ versus $S$ elements, $d_{2}$ will typically be smaller than $d_{1}$ (and at most equally large). If no additional rejection occurs, we stop. Otherwise, we proceed in the same fashion until there are no further rejections.

\footnotetext{
${ }^{9}$ Studentization requires that the average return be divided by its standard error. To obtain valid confidence intervals for the expected return, we must multiply these quantiles with the country's return standard error. Romano and Wolf (2005) advocate the use of studentization, since it is more powerful and gives more appropriate coverage probabilities for individual $\theta_{r_{s}}$, especially when test statistics show different standard deviations. Clearly, the latter applies to our case.
} 


\section{References}

Amihud, Y., 2002. Illiquidity and stock returns: Cross-section and time-series effects. Journal of Financial Markets 5, 31-56.

Andrews, D., 1991. Heteroskedasticity and autocorrelation consistent covariance matrix estimation. Econometrica 59, 817-858.

Arena, M., Haggard, K., Yan, X., 2008. Price momentum and idiosyncratic volatility. The Financial Review 43, 159-190.

Ball, R., Brown, P., 1968. An empirical evaluation of accounting income numbers. Journal of Accounting Research 6, 159-178.

Banerjee, S., Kaniel, R., Kremer, I., 2009. Price drift as an outcome of differences in higher order beliefs. Review of Financial Studies 22, 3707-3734.

Bekaert, G., Erb, C., Harvey, C., Viskanta, T., 1997. What matters for emerging equity market investments. Emerging Markets Quarterly Summer, 17-46.

Bernard, V., Thomas, J., 1989. Post-earnings-announcement drift: Delayed price response or risk premium?. Journal of Accounting Research 27 Supplement, 1-36.

Bonferroni, C., 1936. Teoria statistica delle classi e calcolo delle probabilità. Publicazioni del Istituto Superiore di Scienze Economiche e Commerciali di Firenze 8, 3-62.

Chan, L., Jegadeesh, N., Lakonishok, J., 1996. Momentum strategies. Journal of Finance 51, $1681-1713$.

Chordia, T., Goyal, A., Sadka, G., Sadka, R., Shivakumar, L., 2009. Liquidity and the postearnings-announcement-drift. Financial Analysts Journal 65, 18-32.

Chordia, T., Shivakumar, L., 2006. Earnings and price momentum. Journal of Financial Economics $80,627-656$.

Diether, K., Malloy, C., Scherbina, A., 2002. Differences of opinion and the cross section of stock returns. Journal of Finance 57, 2113-2141.

Fama, E., French, K., 1993. Common risk factors in the returns on stocks and bonds. Journal of Financial Economics 33, 3-56. 
Fama, E., French, K., 1996. Multifactor explanations of asset pricing anomalies. Journal of Finance 51, 55-84.

Griffin, J., Ji, X., Martin, J., 2003. Momentum investing and business cycle risk: Evidence from pole to pole. Journal of Finance 58, 2515-2547.

Griffin, J., Ji, X., Martin, J., 2005. Global momentum strategies. Journal of Portfolio Management $58,23-39$.

Hong, D., C. L., Swaminathan, B., 2003. Earnings momentum in international markets. Working paper. Cornell University.

Hong, H., Lim, T., Stein, J., 2000. Bad news travels slowly: Size, analyst coverage, and the profitability of momentum strategies. Journal of Finance 55, 265-295.

Hong, H., Stein, J., 1999. A unified theory of underreaction, momentum trading and overreaction in asset markets. Journal of Finance 54, 2143-2184.

Hou, K., Peng, L., Xiong, W., 2006. A tale of two anomalies: The implication of investor attention for price and earnings momentum. Working paper. 9th Annual Texas Finance Festival Paper.

Ince, O., Porter, R., 2006. Individual equity return data from Thomson Datastream: Handle with care!. Journal of Financial Research 29, 463-479.

Jegadeesh, N., Titman, S., 1993. Returns to buying winners and selling loosers: Implications for stock market efficiency. Journal of Finance 48, 65-91.

Jegadeesh, N., Titman, S., 2001. Profitability of momentum strategies: An evaluation of alternative explanations. Journal of Finance 56, 699-720.

Kang, Q., Li, C., 2005. Understanding the sources of momentum profits: Stock-specific component versus common-factor component. Working paper. EFA 2004 Maastricht Meetings Paper.

Korajczyk, R., Sadka, R., 2004. Are momentum profits robust to trading costs?. Journal of Finance 59, 1039-1082.

Lehmann, E., Romano, J., 2005. Testing Statistical Hypotheses. Springer, New York. 
Leippold, M., Lohre, H., 2010a. Data snooping and the global accrual anomaly. Working paper. University of Zurich.

Leippold, M., Lohre, H., 2010b. The dispersion effect in international stock returns. Working paper. University of Zurich.

Lesmond, D., Schill, M., Zhou, C., 2004. The illusory nature of momentum profits. Journal of Financial Economics 71, 349-380.

Liew, J., Vassalou, M., 2000. Can book-to-market, size and momentum be risk factors that predict economic growth. Journal of Financial Economics 57, 221-245.

Liu, W., 2006. A liquidity augmented capital asset pricing model. Journal of Financial Economics $82,631-671$.

Lo, A., MacKinlay, A. C., 1990. Data-snooping biases in tests of financial asset pricing models. Review of Financial Studies 3, 431-467.

Lohre, H., 2008. Rationalizing global market anomalies. Ph.D. thesis University of Zurich.

Mendenhall, R., 2004. Arbitrage risk and post-earnings-announcement drift. Journal of Business $77,875-894$.

Newey, W., West, K., 1987. A simple positive-definite heteroskedasticity and autocorrelation consistent covariance matrix. Econometrica 55, 703-708.

Romano, J., Shaikh, A., Wolf, M., 2008. Formalized data snooping based on generalized error rates. Econometric Theory 24, 1-44.

Romano, J., Wolf, M., 2005. Stepwise multiple testing as formalized data snooping. Econometrica $73,1237-1282$.

Rouwenhorst, K., 1998. International momentum strategies. Journal of Finance 53, 267-284.

Rouwenhorst, K., 1999. Local return factors and turnover in emerging stock markets. Journal of Finance 54, 1439-1464.

Sadka, R., 2006. Momentum and post-earnings-announcement drift anomalies: The role of liquidity risk. Journal of Financial Economics 80, 309-349.

Schwert, G. W., 2003. Anomalies and market efficiency. In: Constantinides, G. M., Harris, M., Stulz, R. (Eds.), Handbook of the Economics of Finance. Elsevier, North Holland. 
Scowcroft, A., Sefton, J., 2005. Understanding momentum. Financial Analyst Journal 61, 64-81.

Sloan, R., 1996. Do stock prices fully reflect information in accruals and cash flows about future earnings?. The Accounting Review 71, 289-315.

Sullivan, R., Timmermann, A., White, H., 1999. Data-snooping, technical trading rule performance, and the bootstrap. The Journal of Finance 54, 1647-1691.

Verardo, M., 2009. Heterogenous beliefs and momentum profits. Journal of Financial and Quantitative Analysis 44, 795-822.

White, H., 2000. A reality check for data snooping. Econometrica 68, 1097-1126.

Zhang, X., 2006. Information uncertainty and stock returns. Journal of Finance 61, 105-137. 
Table 1

Country Overview

The table contains descriptive information on the companies that have been domestically traded in the sample period (1988-2009). For further reference we may use abbreviated country codes (Abbr.). The screening of country lists depicts the evolution of the countries' samples. First, we give the Total size of the country lists followed by the number of companies surviving the first screen for Major listings. The column headed Region contains the number of companies surviving the screen eliminating regional listings and the like. The Final screen excludes companies which exhibit free-floating market value below 10 million USD. We further describe this final sample giving the number of a country's dead companies (\#Dead) and the number of companies with at least one I/B/E/S estimate in the sample period (\#I/B/E/S), along with respective percentage values (\%-Dead and \%-I/B/E/S). The last column gives the starting month of the strategy. The table provides information for the U.S. in Panel A, while Panel B covers European countries.

\begin{tabular}{|c|c|c|c|c|c|c|c|c|c|c|c|c|}
\hline \multirow[t]{2}{*}{ Country } & \multirow[t]{2}{*}{ Abbr. } & \multicolumn{4}{|c|}{ Screening of Country Lists } & \multicolumn{6}{|c|}{ Final Sample: FMV> 10} & \multirow{2}{*}{$\begin{array}{l}\text { Start } \\
\text { Date }\end{array}$} \\
\hline & & Total & Major & Final & FMV $>10$ & \#Dead & $\%$ Dead & \#Return & $\%$ Return & $\# \mathrm{I} / \mathrm{B} / \mathrm{E} / \mathrm{S}$ & $\% \mathrm{I} / \mathrm{B} / \mathrm{E} / \mathrm{S}$ & \\
\hline \multicolumn{13}{|l|}{ Panel A: USA } \\
\hline USA & USA & 36659 & 20030 & 7279 & 6272 & 2554 & $40.7 \%$ & 6180 & $98.5 \%$ & 4860 & $77.5 \%$ & Jan 88 \\
\hline \multicolumn{13}{|l|}{ Panel B: Europe } \\
\hline Europe & & 29266 & 10522 & 9383 & 7019 & 1996 & $28.4 \%$ & 6901 & $98.3 \%$ & 5169 & $73.6 \%$ & Jan 88 \\
\hline Austria & A & 360 & 177 & 161 & 119 & 31 & $26.1 \%$ & 115 & $96.6 \%$ & 80 & $67.2 \%$ & Jan 88 \\
\hline Belgium & BEL & 1000 & 288 & 263 & 206 & 40 & $19.4 \%$ & 200 & $97.1 \%$ & 129 & $62.6 \%$ & Jan 88 \\
\hline Denmark & DK & 685 & 365 & 230 & 197 & 55 & $27.9 \%$ & 197 & $100 \%$ & 167 & $84.8 \%$ & Jan 88 \\
\hline Finland & FN & 341 & 190 & 180 & 159 & 42 & $26.4 \%$ & 155 & $97.5 \%$ & 138 & $86.8 \%$ & Aug 90 \\
\hline France & $\mathrm{FR}$ & 2643 & 1458 & 1368 & 945 & 258 & $27.3 \%$ & 917 & $97.0 \%$ & 631 & $66.8 \%$ & Jan 88 \\
\hline Germany & GER & 10740 & 1833 & 1525 & 1017 & 228 & $22.4 \%$ & 991 & $97.4 \%$ & 646 & $63.5 \%$ & Jan 88 \\
\hline Greece & GR & 523 & 393 & 360 & 338 & 57 & $16.9 \%$ & 338 & $100 \%$ & 234 & $69.2 \%$ & Mar 95 \\
\hline Ireland & IRL & 187 & 98 & 94 & 85 & 26 & $30.6 \%$ & 83 & $97.6 \%$ & 63 & $74.1 \%$ & Nov 93 \\
\hline Italy & IL & 794 & 390 & 365 & 345 & 95 & $27.5 \%$ & 345 & $100 \%$ & 305 & $88.4 \%$ & Jan 88 \\
\hline Netherlands & NL & 791 & 272 & 250 & 201 & 77 & $38.3 \%$ & 199 & $99.0 \%$ & 182 & $90.5 \%$ & Jan 88 \\
\hline Norway & NOR & 585 & 328 & 284 & 254 & 98 & $38.6 \%$ & 252 & $99.2 \%$ & 219 & $86.2 \%$ & Jan 88 \\
\hline Portugal & POR & 296 & 146 & 134 & 92 & 48 & $52.2 \%$ & 91 & $98.9 \%$ & 66 & $71.7 \%$ & Jul 93 \\
\hline Spain & $\mathrm{ES}$ & 311 & 204 & 180 & 170 & 51 & $30.0 \%$ & 168 & $98.8 \%$ & 160 & $94.1 \%$ & Jan 88 \\
\hline Sweden & SWE & 1203 & 549 & 441 & 346 & 109 & $31.5 \%$ & 344 & $99.4 \%$ & 280 & $80.9 \%$ & Jan 88 \\
\hline Switzerland & $\mathrm{CH}$ & 1130 & 387 & 316 & 277 & 49 & $17.7 \%$ & 274 & $98.9 \%$ & 217 & $78.3 \%$ & Jan 88 \\
\hline \multirow[t]{3}{*}{ United Kingdom } & UK & 7677 & 3444 & 3232 & 2268 & 732 & $32.3 \%$ & 2232 & $98.4 \%$ & 1652 & $72.8 \%$ & Jan 88 \\
\hline & All & 65738 & 30454 & 16568 & 13206 & 4524 & $34.3 \%$ & 12998 & $98.4 \%$ & 9966 & $75.5 \%$ & \\
\hline & Top 5 & 58922 & 27314 & 13845 & 10848 & 3881 & $35.8 \%$ & 10664 & $98.3 \%$ & 8094 & $74.6 \%$ & \\
\hline
\end{tabular}




\section{Table 2}

\section{Descriptive Statistics of Momentum Quintile Portfolios 1/2}

The table gives average monthly buy-and-hold returns and volatility of quintile portfolios that are built monthly dependent on the price momentum ranking (left panel) or dependent on the earnings momentum ranking (right panel). All figures refer to the period from January 1988 to March 2009. We give the return differential of the respective hedge strategies along with the according $t$-statistic in parentheses. The table also gives the two risk proxies beta and size. Both are gathered using data of the whole period, in particular beta arises from a standard CAPM regression and size is measured as the average of log(marketvalue). Note that we do not compute the size proxy for the hedge strategies but give the $t$-statistic belonging to the return differential.

$$
\text { Price Momentum Ranking }
$$

\begin{tabular}{|c|c|c|c|c|c|c|c|c|c|c|c|c|c|c|c|}
\hline Country & & Lowest & 2 & 3 & 4 & Highest & Price & Earnings & Lowest & 2 & 3 & 4 & Highest & & Country \\
\hline \multirow{4}{*}{ USA } & Return & 0.70 & 0.90 & 1.02 & 1.12 & 1.43 & 0.72 & 0.46 & 0.92 & 0.85 & 0.80 & 1.08 & 1.38 & Return & \multirow{4}{*}{ USA } \\
\hline & Volatility & 7.01 & 5.12 & 4.52 & 4.56 & 6.19 & 3.91 & 2.39 & 6.60 & 5.34 & 4.64 & 4.85 & 5.66 & Volatility & \\
\hline & Beta & 1.22 & 0.88 & 0.76 & 0.78 & 1.05 & -0.16 & -0.11 & 1.18 & 0.94 & 0.79 & 0.83 & 1.00 & Beta & \\
\hline & Size & 19.81 & 20.33 & 20.50 & 20.54 & 20.27 & $(2.99)$ & $(3.12)$ & 19.51 & 20.20 & 20.64 & 20.66 & 20.09 & Size & \\
\hline \multirow{4}{*}{ Europe } & Return & 0.31 & 0.64 & 0.88 & 1.05 & 1.41 & 1.11 & 0.76 & 0.52 & 0.62 & 0.73 & 0.87 & 1.28 & Return & \multirow{4}{*}{ Europe } \\
\hline & Volatility & 5.74 & 4.45 & 4.07 & 4.09 & 4.77 & 3.24 & 1.65 & 5.26 & 4.64 & 4.18 & 4.15 & 4.49 & Volatility & \\
\hline & Beta & 1.27 & 0.99 & 0.91 & 0.91 & 1.04 & -0.23 & -0.13 & 1.20 & 1.06 & 0.94 & 0.93 & 1.02 & Beta & \\
\hline & Size & 20.38 & 20.94 & 21.17 & 21.29 & 21.16 & $(5.51)$ & $(7.42)$ & 20.00 & 21.05 & 21.44 & 21.46 & 20.67 & Size & \\
\hline \multirow{4}{*}{ Austria } & Return & 0.61 & 0.72 & 0.72 & 1.01 & 1.24 & 0.63 & 0.40 & 0.72 & 0.86 & 0.67 & 0.74 & 1.12 & Return & \multirow{4}{*}{ UK } \\
\hline & Volatility & 6.79 & 5.98 & 5.89 & 6.22 & 6.22 & 5.10 & 4.50 & 7.24 & 6.15 & 5.80 & 5.45 & 6.06 & Volatility & \\
\hline & Beta & 1.18 & 1.18 & 1.18 & 1.20 & 1.18 & 0.00 & -0.07 & 1.40 & 1.19 & 1.13 & 1.03 & 1.13 & Beta & \\
\hline & Size & 19.08 & 19.48 & 19.67 & 19.81 & 19.78 & $(2.00)$ & (1.44) & 19.16 & 19.54 & 19.72 & 19.71 & 19.66 & Size & \\
\hline \multirow{4}{*}{ Belgium } & Return & 0.37 & 0.51 & 0.76 & 1.07 & 1.31 & 0.94 & 0.70 & 0.56 & 0.65 & 0.66 & 0.95 & 1.26 & Return & \multirow{4}{*}{ Ireland } \\
\hline & Volatility & 5.62 & 4.80 & 4.55 & 4.63 & 4.97 & 3.72 & 2.95 & 5.60 & 4.99 & 4.38 & 4.73 & 4.93 & Volatility & \\
\hline & Beta & 1.32 & 1.15 & 1.14 & 1.13 & 1.16 & -0.16 & -0.05 & 1.33 & 1.22 & 1.09 & 1.11 & 1.19 & Beta & \\
\hline & Size & 19.60 & 20.04 & 20.11 & 20.21 & 20.07 & $(4.10)$ & $(3.83)$ & 19.31 & 20.08 & 20.30 & 20.31 & 19.79 & Size & \\
\hline \multirow{4}{*}{ Denmark } & Return & 0.51 & 0.60 & 0.67 & 1.21 & 1.46 & 0.95 & 1.15 & 0.38 & 0.51 & 0.75 & 0.92 & 1.53 & Return & \multirow{4}{*}{ Germany } \\
\hline & Volatility & 6.64 & 5.00 & 4.68 & 5.10 & 5.33 & 4.24 & 4.25 & 5.71 & 5.30 & 4.95 & 4.59 & 5.63 & Volatility & \\
\hline & Beta & 1.35 & 1.11 & 1.04 & 0.99 & 1.11 & -0.24 & -0.01 & 1.23 & 1.17 & 1.06 & 0.97 & 1.14 & Beta & \\
\hline & Size & 20.74 & 21.10 & 21.20 & 21.24 & 21.35 & $(3.63)$ & $(4.38)$ & 20.51 & 21.09 & 21.29 & 21.40 & 21.01 & Size & \\
\hline \multirow{4}{*}{ Finland } & Return & 0.65 & 1.10 & 1.39 & 1.27 & 1.46 & 0.81 & 0.85 & 0.72 & 0.68 & 0.75 & 0.97 & 1.57 & Return & \multirow{4}{*}{ Austria } \\
\hline & Volatility & 8.34 & 6.72 & 6.62 & 6.35 & 6.83 & 5.84 & 4.65 & 7.81 & 7.13 & 6.59 & 5.76 & 6.45 & Volatility & \\
\hline & Beta & 1.11 & 0.91 & 0.91 & 0.86 & 0.87 & -0.24 & -0.10 & 1.06 & 1.00 & 0.91 & 0.80 & 0.86 & Beta & \\
\hline & Size & 19.47 & 19.65 & 19.66 & 19.69 & 19.83 & $(2.23)$ & $(2.96)$ & 19.31 & 19.65 & 19.75 & 19.79 & 19.51 & Size & \\
\hline \multirow{4}{*}{ France } & Return & 0.58 & 0.82 & 1.05 & 1.16 & 1.53 & 0.96 & 0.68 & 0.68 & 0.79 & 0.86 & 1.04 & 1.36 & Return & \multirow{4}{*}{ Switzerland } \\
\hline & Volatility & 7.16 & 5.62 & 5.20 & 5.11 & 5.72 & 3.89 & 2.74 & 6.72 & 5.89 & 5.26 & 5.22 & 5.55 & Volatility & \\
\hline & Beta & 1.38 & 1.09 & 1.01 & 1.01 & 1.11 & -0.27 & -0.16 & 1.33 & 1.17 & 1.06 & 1.02 & 1.11 & Beta & \\
\hline & Size & 19.52 & 20.13 & 20.29 & 20.31 & 20.14 & $(3.98)$ & $(4.01)$ & 19.21 & 20.05 & 20.34 & 20.35 & 19.87 & Size & \\
\hline \multirow{4}{*}{ Germany } & Return & 0.02 & 0.47 & 0.62 & 0.87 & 1.12 & 1.10 & 0.76 & 0.11 & 0.29 & 0.42 & 0.51 & 0.88 & Return & \multirow{4}{*}{ France } \\
\hline & Volatility & 7.17 & 5.49 & 4.77 & 4.63 & 4.86 & 4.56 & 2.35 & 5.96 & 5.57 & 5.15 & 5.00 & 5.41 & Volatility & \\
\hline & Beta & 1.44 & 1.14 & 0.97 & 0.94 & 0.98 & -0.46 & -0.01 & 1.26 & 1.20 & 1.10 & 1.06 & 1.14 & Beta & \\
\hline & Size & 19.49 & 19.94 & 20.12 & 20.21 & 20.13 & (3.91) & $(5.23)$ & 19.36 & 20.03 & 20.38 & 20.19 & 19.91 & Size & \\
\hline \multirow{4}{*}{ Greece } & Return & 0.70 & 0.92 & 0.99 & 1.58 & 1.92 & 1.22 & 0.23 & 0.98 & 0.54 & 1.13 & 0.86 & 1.21 & Return & \multirow{4}{*}{ Italy } \\
\hline & Volatility & 10.22 & 9.75 & 9.28 & 10.04 & 11.28 & 6.43 & 4.34 & 10.64 & 9.33 & 9.93 & 9.61 & 9.62 & Volatility & \\
\hline & Beta & 0.81 & 0.80 & 0.76 & 0.80 & 0.87 & 0.06 & -0.03 & 0.85 & 0.76 & 0.80 & 0.78 & 0.77 & Beta & \\
\hline & Size & 19.23 & 19.54 & 19.62 & 19.79 & 19.63 & (3.06) & $(0.85)$ & 19.26 & 19.49 & 19.61 & 19.68 & 19.36 & Size & \\
\hline
\end{tabular}


Table 3

Descriptive Statistics of Momentum Quintile Portfolios 2/2

The table gives average monthly buy-and-hold returns and volatility of quintile portfolios that are built monthly dependent on the price momentum ranking (left panel) or dependent on the earnings momentum ranking (right panel). All figures refer to the period from January 1988 to March 2009. We give the return differential of the respective hedge strategies along with the according $t$-statistic in parentheses. The table also gives the two risk proxies beta and size. Both are gathered using data of the whole period, in particular beta arises from a standard CAPM regression and size is measured as the average of log(marketvalue). Note that we do not compute the size proxy for the hedge strategies but give the $t$-statistic belonging to the return differential.

$$
\text { Price Momentum Ranking Hedge Strategies Earnings Momentum Ranking }
$$

\begin{tabular}{|c|c|c|c|c|c|c|c|c|c|c|c|c|c|c|c|}
\hline Country & & Lowest & 2 & 3 & 4 & Highest & Price & Earnings & Lowest & 2 & 3 & 4 & Highest & & Country \\
\hline \multirow{4}{*}{ Ireland } & Return & 0.76 & 0.54 & 1.25 & 1.06 & 1.44 & 0.68 & 1.32 & 0.44 & 0.74 & 0.95 & 0.93 & 1.76 & Return & \multirow{4}{*}{ Greece } \\
\hline & Volatility & 7.81 & 6.56 & 5.31 & 5.72 & 6.30 & 6.37 & 6.17 & 7.53 & 6.97 & 5.78 & 6.01 & 6.20 & Volatility & \\
\hline & Beta & 0.97 & 0.90 & 0.72 & 0.70 & 0.81 & -0.16 & -0.16 & 0.99 & 0.91 & 0.70 & 0.76 & 0.83 & Beta & \\
\hline & Size & 20.07 & 20.35 & 20.39 & 20.25 & 20.11 & (1.72) & $(3.45)$ & 19.58 & 20.67 & 21.07 & 20.88 & 19.82 & Size & \\
\hline \multirow{4}{*}{ Italy } & Return & 0.05 & 0.45 & 0.48 & 0.69 & 1.23 & 1.18 & 0.26 & 0.41 & 0.33 & 0.48 & 0.70 & 0.68 & Return & \multirow{4}{*}{ Spain } \\
\hline & Volatility & 7.74 & 6.65 & 6.40 & 5.98 & 6.38 & 4.35 & 3.21 & 7.04 & 6.85 & 6.91 & 6.03 & 6.17 & Volatility & \\
\hline & Beta & 1.15 & 1.01 & 0.96 & 0.89 & 0.93 & -0.22 & -0.14 & 1.06 & 1.05 & 1.02 & 0.88 & 0.94 & Beta & \\
\hline & Size & 20.26 & 20.57 & 20.66 & 20.65 & 20.49 & $(4.38)$ & $(1.33)$ & 19.91 & 20.70 & 20.77 & 20.71 & 20.21 & Size & \\
\hline \multirow{4}{*}{ Netherlands } & Return & 0.67 & 0.94 & 1.06 & 1.12 & 1.38 & 0.71 & 0.82 & 0.64 & 0.77 & 0.85 & 1.10 & 1.46 & Return & \multirow{4}{*}{ Portugal } \\
\hline & Volatility & 6.42 & 5.08 & 4.80 & 4.65 & 5.59 & 4.10 & 3.47 & 6.30 & 5.18 & 4.79 & 4.84 & 5.35 & Volatility & \\
\hline & Beta & 1.20 & 0.98 & 0.92 & 0.89 & 1.03 & -0.17 & -0.13 & 1.18 & 0.99 & 0.92 & 0.91 & 1.01 & Beta & \\
\hline & Size & 19.38 & 19.70 & 19.80 & 19.82 & 19.77 & $(2.80)$ & $(3.82)$ & 18.93 & 19.80 & 20.21 & 20.02 & 19.42 & Size & \\
\hline \multirow{4}{*}{ Norway } & Return & 0.59 & 0.74 & 1.06 & 0.99 & 1.71 & 1.12 & 0.61 & 0.95 & 0.76 & 0.69 & 1.01 & 1.56 & Return & \multirow{4}{*}{ Netherlands } \\
\hline & Volatility & 8.29 & 6.49 & 6.05 & 6.51 & 7.53 & 5.78 & 5.01 & 7.88 & 6.61 & 6.83 & 6.44 & 6.60 & Volatility & \\
\hline & Beta & 1.08 & 0.85 & 0.78 & 0.82 & 0.94 & -0.14 & -0.11 & 1.03 & 0.88 & 0.88 & 0.82 & 0.82 & Beta & \\
\hline & Size & 21.50 & 21.73 & 21.83 & 21.88 & 21.85 & $(3.14)$ & $(1.98)$ & 21.59 & 21.58 & 21.67 & 21.74 & 21.79 & Size & \\
\hline \multirow{4}{*}{ Portugal } & Return & 0.73 & 1.26 & 1.13 & 1.12 & 1.29 & 0.55 & 0.81 & 0.50 & 0.82 & 0.88 & 1.06 & 1.31 & Return & \multirow{4}{*}{ Belgium } \\
\hline & Volatility & 7.12 & 6.54 & 6.45 & 5.97 & 6.43 & 5.96 & 5.14 & 6.85 & 6.32 & 5.95 & 6.06 & 7.05 & Volatility & \\
\hline & Beta & 0.99 & 0.91 & 0.88 & 0.82 & 0.78 & -0.21 & 0.02 & 0.97 & 0.88 & 0.83 & 0.79 & 0.92 & Beta & \\
\hline & Size & 19.52 & 19.96 & 20.19 & 20.06 & 19.89 & $(1.50)$ & $(2.55)$ & 19.51 & 20.13 & 20.00 & 20.01 & 19.73 & Size & \\
\hline \multirow{4}{*}{ Spain } & Return & 0.38 & 0.75 & 0.89 & 0.92 & 1.18 & 0.80 & 0.55 & 0.51 & 0.53 & 0.82 & 0.93 & 1.06 & Return & \multirow{4}{*}{ Sweden } \\
\hline & Volatility & 6.79 & 5.67 & 5.27 & 5.13 & 5.58 & 4.05 & 3.72 & 6.93 & 5.63 & 5.30 & 5.19 & 5.67 & Volatility & \\
\hline & Beta & 1.10 & 0.93 & 0.87 & 0.83 & 0.88 & -0.22 & -0.12 & 1.12 & 0.93 & 0.87 & 0.84 & 0.91 & Beta & \\
\hline & Size & 19.97 & 20.34 & 20.51 & 20.59 & 20.43 & (3.19) & $(2.37)$ & 19.60 & 20.44 & 20.60 & 20.75 & 20.26 & Size & \\
\hline \multirow{4}{*}{ Sweden } & Return & 0.98 & 1.05 & 1.13 & 1.31 & 1.52 & 0.53 & 0.73 & 0.69 & 0.94 & 1.20 & 1.31 & 1.42 & Return & \multirow{4}{*}{ Norway } \\
\hline & Volatility & 7.90 & 5.97 & 5.64 & 5.82 & 6.35 & 4.96 & 4.13 & 7.07 & 6.45 & 6.15 & 5.75 & 6.10 & Volatility & \\
\hline & Beta & 0.95 & 0.72 & 0.67 & 0.68 & 0.73 & -0.21 & -0.12 & 0.85 & 0.79 & 0.74 & 0.68 & 0.72 & Beta & \\
\hline & Size & 21.82 & 22.07 & 22.16 & 22.23 & 22.24 & (1.74) & $(2.87)$ & 21.46 & 22.07 & 22.26 & 22.27 & 21.89 & Size & \\
\hline \multirow{4}{*}{ Switzerland } & Return & 0.36 & 0.54 & 0.64 & 0.97 & 1.25 & 0.90 & 0.53 & 0.49 & 0.64 & 0.69 & 0.82 & 1.02 & Return & \multirow{4}{*}{ Denmark } \\
\hline & Volatility & 6.38 & 5.01 & 4.66 & 4.71 & 5.32 & 4.06 & 2.97 & 6.10 & 5.11 & 4.52 & 4.69 & 5.07 & Volatility & \\
\hline & Beta & 1.35 & 1.10 & 1.03 & 1.03 & 1.12 & -0.23 & -0.14 & 1.32 & 1.13 & 0.99 & 1.02 & 1.10 & Beta & \\
\hline & Size & 19.90 & 20.24 & 20.37 & 20.50 & 20.41 & (3.57) & $(2.90)$ & 19.65 & 20.38 & 20.56 & 20.53 & 20.19 & Size & \\
\hline \multirow{4}{*}{ UK } & Return & 0.26 & 0.67 & 0.86 & 0.96 & 1.16 & 0.91 & 0.63 & 0.61 & 0.52 & 0.85 & 0.92 & 1.24 & Return & \multirow{4}{*}{ Finland } \\
\hline & Volatility & 5.68 & 4.33 & 4.12 & 4.19 & 4.86 & 3.92 & 2.20 & 4.78 & 4.46 & 4.42 & 4.22 & 4.51 & Volatility & \\
\hline & Beta & 0.91 & 0.74 & 0.71 & 0.73 & 0.85 & -0.06 & -0.05 & 0.85 & 0.78 & 0.77 & 0.74 & 0.79 & Beta & \\
\hline & Size & 24.75 & 24.95 & 24.99 & 24.89 & 24.62 & (3.74) & $(4.65)$ & 24.60 & 24.93 & 25.13 & 24.91 & 24.47 & Size & \\
\hline
\end{tabular}


Table 4

Time-Series-Regressions of Price Momentum Portfolios

The table gives the results of a regression according to equation (3) using 255 monthly returns ranging from January 1988 to March 2009 along with the according $t$-statistics. Portfolio 1 refers to the loser quintile, portfolio 5 refers to the winner quintile, and portfolio 5-1 is the long-short portfolio (winner-loser).

\begin{tabular}{|c|c|c|c|c|c|c|c|c|c|c|}
\hline & & \multicolumn{9}{|c|}{ Fama-French Model } \\
\hline & & $\alpha$ & $\beta$ & $\gamma$ & $\delta$ & $t(\alpha)$ & $t(\beta)$ & $t(\gamma)$ & $t(\delta)$ & $\begin{array}{r}\text { Adj. } \\
R^{2}\end{array}$ \\
\hline \multirow{3}{*}{ USA } & 1 & -0.77 & 1.33 & -0.29 & 0.09 & -5.21 & 42.87 & -7.46 & 1.77 & 88.9 \\
\hline & 5 & 0.05 & 1.06 & -0.05 & -0.29 & 0.33 & 32.38 & -1.26 & -5.38 & 84.3 \\
\hline & $5-1$ & 0.83 & -0.27 & 0.24 & -0.38 & 3.70 & -5.84 & 4.08 & -4.94 & 19.7 \\
\hline \multirow{3}{*}{ Europe } & 1 & -0.63 & 1.27 & -0.35 & 0.28 & -5.16 & 42.31 & -7.92 & 4.62 & 88.6 \\
\hline & 5 & 0.60 & 1.06 & -0.26 & -0.03 & 4.90 & 35.50 & -5.86 & -0.56 & 83.7 \\
\hline & $5-1$ & 1.23 & -0.21 & 0.09 & -0.32 & 6.43 & -4.45 & 1.33 & -3.31 & 12.5 \\
\hline \multirow{3}{*}{ Austria } & 1 & -0.32 & 1.17 & -0.12 & 0.11 & -1.18 & 19.06 & -1.90 & 2.09 & 61.5 \\
\hline & 5 & 0.36 & 1.20 & -0.12 & -0.02 & 1.73 & 25.50 & -2.39 & -0.62 & 72.8 \\
\hline & $5-1$ & 0.67 & 0.04 & 0.00 & -0.13 & 2.09 & 0.48 & 0.05 & -2.14 & 0.6 \\
\hline \multirow{3}{*}{ Belgium } & 1 & -0.65 & 1.30 & -0.02 & 0.09 & -3.78 & 28.07 & -0.82 & 2.24 & 76.8 \\
\hline & 5 & 0.39 & 1.17 & -0.01 & -0.06 & 2.48 & 27.56 & -0.39 & -1.76 & 75.2 \\
\hline & $5-1$ & 1.04 & -0.13 & 0.01 & -0.15 & 4.52 & -2.09 & 0.35 & -2.87 & 4.6 \\
\hline \multirow{3}{*}{ Denmark } & 1 & -0.50 & 1.34 & -0.15 & -0.07 & -2.18 & 23.92 & -2.24 & -1.46 & 69.8 \\
\hline & 5 & 0.52 & 1.11 & -0.11 & -0.13 & 3.02 & 26.56 & -2.34 & -3.91 & 74.2 \\
\hline & $5-1$ & 1.02 & -0.23 & 0.03 & -0.06 & 3.91 & -3.69 & 0.44 & -1.27 & 4.9 \\
\hline \multirow{3}{*}{ Finland } & 1 & -0.67 & 1.11 & -0.02 & -0.04 & -2.44 & 24.83 & -0.37 & -1.41 & 75.6 \\
\hline & 5 & 0.35 & 0.82 & -0.18 & -0.06 & 1.43 & 20.88 & -3.61 & -2.31 & 71.6 \\
\hline & $5-1$ & 1.02 & -0.28 & -0.16 & -0.02 & 2.72 & -4.64 & -2.07 & -0.47 & 7.6 \\
\hline \multirow{3}{*}{ France } & 1 & -1.10 & 1.39 & -0.19 & 0.21 & -6.25 & 37.57 & -3.64 & 4.93 & 85.1 \\
\hline & 5 & 0.12 & 1.13 & -0.26 & -0.06 & 0.85 & 39.49 & -6.29 & -1.89 & 86.1 \\
\hline & $5-1$ & 1.22 & -0.26 & -0.06 & -0.27 & 5.42 & -5.56 & -0.95 & -5.02 & 18.1 \\
\hline \multirow{3}{*}{ Germany } & 1 & -0.84 & 1.44 & -0.25 & 0.02 & -3.67 & 26.79 & -4.44 & 0.39 & 74.8 \\
\hline & 5 & 0.43 & 0.97 & -0.17 & -0.03 & 2.76 & 26.48 & -4.48 & -0.67 & 74.5 \\
\hline & $5-1$ & 1.26 & -0.47 & 0.08 & -0.05 & 4.86 & -7.56 & 1.20 & -0.74 & 18.3 \\
\hline \multirow{3}{*}{ Greece } & 1 & -0.50 & 0.82 & 0.12 & -0.19 & -1.50 & 28.04 & 1.42 & -1.80 & 81.8 \\
\hline & 5 & 0.77 & 0.89 & -0.02 & -0.44 & 1.97 & 25.77 & -0.21 & -3.58 & 79.3 \\
\hline & 5-1 & 1.27 & 0.07 & -0.14 & -0.25 & 2.60 & 1.57 & -1.13 & -1.64 & 1.8 \\
\hline \multirow{3}{*}{ Ireland } & 1 & -0.26 & 0.92 & 0.02 & 0.12 & -0.70 & 13.86 & 0.32 & 2.34 & 51.2 \\
\hline & 5 & 0.42 & 0.86 & -0.01 & -0.15 & 1.47 & 16.95 & -0.26 & -3.83 & 56.7 \\
\hline & $5-1$ & 0.67 & -0.06 & -0.03 & -0.26 & 1.64 & -0.83 & -0.47 & -4.74 & 10.0 \\
\hline \multirow{3}{*}{ Italy } & 1 & -0.71 & 1.16 & -0.17 & 0.01 & -3.66 & 36.65 & -3.44 & 0.28 & 84.2 \\
\hline & 5 & 0.58 & 0.93 & -0.03 & -0.12 & 3.27 & 32.58 & -0.70 & -2.92 & 80.8 \\
\hline & $5-1$ & 1.29 & -0.22 & 0.14 & -0.14 & 4.98 & -5.26 & 2.11 & -2.20 & 11.3 \\
\hline \multirow{3}{*}{ Netherlands } & 1 & -0.29 & 1.13 & 0.04 & 0.17 & -1.86 & 32.24 & 1.22 & 4.84 & 85.2 \\
\hline & 5 & 0.56 & 1.05 & 0.00 & -0.05 & 3.64 & 30.22 & 0.07 & -1.35 & 80.9 \\
\hline & $5-1$ & 0.85 & -0.08 & -0.03 & -0.21 & 3.46 & -1.41 & -0.73 & -3.91 & 8.8 \\
\hline \multirow{3}{*}{ Norway } & 1 & -0.95 & 1.09 & -0.26 & 0.14 & -3.47 & 25.64 & -3.23 & 2.63 & 73.1 \\
\hline & 5 & 0.41 & 0.95 & -0.06 & -0.03 & 1.44 & 21.60 & -0.71 & -0.57 & 65.2 \\
\hline & $5-1$ & 1.36 & -0.14 & 0.20 & -0.18 & 3.78 & -2.53 & 1.91 & -2.45 & 5.0 \\
\hline \multirow{3}{*}{ Portugal } & 1 & -1.10 & 1.00 & 0.20 & -0.07 & -2.87 & 13.43 & 1.71 & -0.83 & 48.3 \\
\hline & 5 & -0.17 & 0.77 & -0.01 & -0.17 & -0.45 & 10.30 & -0.09 & -1.84 & 36.4 \\
\hline & $5-1$ & 0.93 & -0.23 & -0.21 & -0.09 & 2.11 & -2.69 & -1.57 & -0.89 & 3.6 \\
\hline \multirow{3}{*}{ Spain } & 1 & -0.60 & 1.09 & -0.03 & -0.06 & -3.63 & 37.40 & -0.96 & -1.52 & 85.1 \\
\hline & 5 & 0.29 & 0.88 & -0.03 & -0.07 & 1.86 & 32.39 & -0.92 & -1.91 & 81.1 \\
\hline & $5-1$ & 0.89 & -0.22 & 0.00 & -0.01 & 3.64 & -5.06 & 0.07 & -0.17 & 8.4 \\
\hline & 1 & -0.15 & 0.94 & -0.26 & 0.06 & -0.57 & 25.69 & -4.90 & 1.55 & 73.6 \\
\hline Sweden & 5 & 0.55 & 0.73 & -0.27 & 0.03 & 2.48 & 23.12 & -5.82 & 0.83 & 70.1 \\
\hline & $5-1$ & 0.69 & -0.22 & 0.00 & -0.03 & 2.31 & -5.07 & -0.07 & -0.72 & 8.3 \\
\hline & 1 & -0.58 & 1.28 & -0.06 & 0.12 & -3.77 & 32.46 & -1.62 & 2.98 & 85.8 \\
\hline Switzerland & 5 & 0.43 & 1.14 & 0.01 & -0.05 & 3.16 & 32.42 & 0.39 & -1.34 & 83.8 \\
\hline & $5-1$ & 1.01 & -0.14 & 0.08 & -0.16 & 4.10 & -2.19 & 1.22 & -2.59 & 8.4 \\
\hline & 1 & -0.26 & 0.89 & -0.15 & 0.23 & -1.23 & 20.46 & -3.79 & 2.90 & 64.8 \\
\hline UK & 5 & 0.68 & 0.86 & -0.08 & -0.20 & 4.43 & 26.96 & -2.78 & -3.59 & 74.5 \\
\hline & $5-1$ & 0.94 & -0.04 & 0.07 & -0.43 & 4.04 & -0.77 & 1.61 & -4.99 & 9.9 \\
\hline
\end{tabular}


Table 5

Time-Series-Regressions of Earnings Momentum Portfolios

The table gives the results of a regression according to equation (3) using 255 monthly returns ranging from January 1988 to March 2009 along with the according $t$-statistics. Portfolio 1 refers to the negative earnings revisions quintile, portfolio 5 refers to the positive earnings revision quintile, and portfolio 5 - 1 is the long-short portfolio (positive-negative).

\begin{tabular}{|c|c|c|c|c|c|c|c|c|c|c|}
\hline & & & & & Fams & French & Model & & & \\
\hline & & $\alpha$ & $\beta$ & $\gamma$ & $\delta$ & $t(\alpha)$ & $t(\beta)$ & $t(\gamma)$ & $t(\delta)$ & $\begin{array}{r}\text { Adj. } \\
R^{2}\end{array}$ \\
\hline \multirow{3}{*}{ USA } & 1 & -0.59 & 1.23 & -0.09 & 0.14 & -5.25 & 52.19 & -3.16 & 3.73 & 92.8 \\
\hline & 5 & 0.07 & 1.09 & -0.24 & -0.06 & 0.66 & 48.43 & -8.47 & -1.76 & 91.1 \\
\hline & $5-1$ & 0.66 & -0.14 & -0.15 & -0.21 & 5.09 & -5.16 & -4.26 & -4.68 & 26.7 \\
\hline \multirow{3}{*}{ Europe } & 1 & -0.40 & 1.20 & -0.25 & 0.23 & -4.52 & 55.08 & $\begin{array}{l}-7.76 \\
\end{array}$ & 5.14 & 92.8 \\
\hline & 5 & 0.44 & 1.03 & -0.24 & 0.12 & 5.21 & 49.89 & -7.93 & 2.88 & 91.3 \\
\hline & $5-1$ & 0.84 & -0.17 & 0.01 & -0.11 & 9.19 & -7.70 & 0.26 & -2.35 & 22.1 \\
\hline \multirow{3}{*}{ Austria } & 1 & -0.29 & 1.39 & -0.11 & 0.10 & -1.28 & 27.01 & -2.06 & 2.39 & 76.0 \\
\hline & 5 & 0.25 & 1.11 & 0.06 & 0.04 & 1.18 & 23.19 & 1.17 & 1.06 & 70.3 \\
\hline & $5-1$ & 0.53 & -0.28 & 0.17 & -0.06 & 1.96 & -4.43 & 2.60 & -1.16 & 8.8 \\
\hline \multirow{3}{*}{ Belgium } & 1 & -0.49 & 1.31 & -0.02 & 0.10 & -2.97 & 29.57 & -0.85 & 2.55 & 78.6 \\
\hline & 5 & 0.28 & 1.19 & -0.03 & 0.01 & 2.07 & 32.15 & -1.67 & 0.39 & 80.8 \\
\hline & $5-1$ & 0.77 & -0.12 & -0.01 & -0.08 & 4.21 & -2.41 & -0.49 & -2.00 & 3.5 \\
\hline \multirow{3}{*}{ Denmark } & 1 & -0.56 & 1.23 & 0.02 & 0.01 & -3.25 & 29.18 & 0.50 & 0.39 & 77.0 \\
\hline & 5 & 0.59 & 1.14 & -0.05 & -0.07 & 2.95 & 23.29 & -0.95 & -1.82 & 68.3 \\
\hline & $5-1$ & 1.16 & -0.10 & -0.08 & -0.08 & 4.35 & -1.48 & -1.04 & -1.63 & 1.3 \\
\hline \multirow{3}{*}{ Finland } & 1 & -0.37 & 1.04 & -0.07 & 0.04 & -1.53 & 26.68 & -1.38 & 1.63 & 77.9 \\
\hline & 5 & 0.60 & 0.82 & -0.12 & 0.00 & 2.84 & 23.77 & -2.77 & 0.14 & 74.7 \\
\hline & $5-1$ & 0.97 & -0.22 & -0.05 & -0.04 & 3.33 & -4.59 & -0.88 & -1.24 & 7.8 \\
\hline \multirow{3}{*}{ France } & 1 & -0.91 & 1.34 & -0.20 & 0.18 & -6.64 & 46.51 & -4.89 & 5.46 & 89.7 \\
\hline & 5 & -0.01 & 1.12 & -0.14 & 0.00 & -0.11 & 47.77 & -4.23 & 0.11 & 90.0 \\
\hline & $5-1$ & 0.90 & -0.22 & 0.06 & -0.18 & 5.79 & -6.68 & 1.28 & -4.75 & 20.9 \\
\hline \multirow{3}{*}{ Germany } & 1 & -0.69 & 1.26 & -0.17 & 0.13 & -4.27 & 33.30 & -4.32 & 3.06 & 81.8 \\
\hline & 5 & 0.14 & 1.14 & -0.21 & 0.03 & 0.98 & 33.53 & -5.89 & 0.94 & 82.3 \\
\hline & $5-1$ & 0.83 & -0.12 & -0.04 & -0.09 & 5.73 & -3.62 & -1.07 & -2.47 & 5.5 \\
\hline \multirow{3}{*}{ Greece } & 1 & -0.17 & 0.86 & 0.02 & -0.21 & -0.50 & 28.32 & 0.27 & -1.88 & 81.7 \\
\hline & 5 & 0.16 & 0.78 & 0.08 & -0.31 & 0.52 & 29.10 & 1.00 & -3.18 & 82.5 \\
\hline & $5-1$ & 0.33 & -0.08 & 0.05 & -0.10 & 1.03 & -2.65 & 0.66 & -1.00 & 3.5 \\
\hline \multirow{3}{*}{ Ireland } & 1 & -0.60 & 0.96 & 0.02 & 0.06 & -1.56 & 13.82 & 0.34 & 1.26 & 54.4 \\
\hline & 5 & 0.78 & 0.84 & -0.04 & -0.05 & 2.55 & 15.14 & -1.08 & -1.24 & 56.9 \\
\hline & $5-1$ & 1.38 & -0.12 & -0.06 & -0.12 & 3.02 & -1.42 & -1.00 & -1.89 & 2.9 \\
\hline \multirow{3}{*}{ Italy } & 1 & -0.32 & 1.06 & -0.11 & 0.10 & -1.91 & 38.50 & -2.52 & 2.46 & 85.5 \\
\hline & 5 & -0.01 & 0.93 & -0.02 & 0.07 & -0.08 & 40.32 & -0.43 & 2.05 & 86.6 \\
\hline & $5-1$ & 0.31 & -0.12 & 0.09 & -0.03 & 1.58 & -3.85 & 1.86 & -0.63 & 5.5 \\
\hline \multirow{3}{*}{ Netherlands } & 1 & -0.33 & 1.13 & 0.05 & 0.12 & -2.18 & 33.70 & 1.88 & 3.59 & 85.7 \\
\hline & 5 & 0.62 & 1.02 & 0.00 & -0.04 & 4.61 & 33.77 & 0.06 & -1.24 & 84.1 \\
\hline & $5-1$ & 0.95 & -0.11 & -0.05 & -0.15 & 4.60 & -2.43 & -1.33 & -3.42 & 10.2 \\
\hline \multirow{3}{*}{ Norway } & 1 & -0.49 & 1.03 & -0.07 & 0.11 & -1.86 & 25.46 & -0.87 & 2.13 & 73.0 \\
\hline & 5 & 0.32 & 0.83 & -0.12 & 0.05 & 1.29 & 21.83 & -1.63 & 0.95 & 66.0 \\
\hline & $5-1$ & 0.80 & -0.20 & -0.05 & -0.07 & 2.61 & -4.20 & -0.56 & -1.05 & 6.9 \\
\hline \multirow{3}{*}{ Portugal } & 1 & -1.12 & 0.98 & 0.19 & -0.18 & -3.20 & 14.12 & 1.75 & -2.07 & 49.9 \\
\hline & 5 & -0.24 & 0.91 & -0.10 & -0.09 & -0.60 & 11.82 & -0.83 & -0.96 & 41.3 \\
\hline & $5-1$ & 0.89 & -0.06 & -0.29 & 0.08 & 2.40 & -0.85 & -2.55 & 0.95 & 2.1 \\
\hline \multirow{3}{*}{ Spain } & 1 & -0.47 & 1.11 & -0.04 & -0.04 & -2.71 & 36.46 & -1.17 & -0.95 & 84.5 \\
\hline & 5 & 0.15 & 0.91 & -0.04 & -0.01 & 1.00 & 35.55 & -1.23 & -0.30 & 83.8 \\
\hline & $5-1$ & 0.62 & -0.20 & 0.01 & 0.03 & 2.75 & -5.19 & 0.11 & 0.54 & 9.1 \\
\hline \multirow{3}{*}{ Sweden } & 1 & -0.43 & 0.86 & -0.22 & 0.13 & -1.97 & 27.32 & -4.69 & 3.98 & 75.8 \\
\hline & 5 & 0.41 & 0.72 & -0.23 & 0.10 & 2.03 & 25.14 & -5.43 & 3.15 & 73.0 \\
\hline & $5-1$ & 0.84 & -0.14 & -0.01 & -0.04 & 3.30 & -3.75 & -0.24 & -0.95 & 4.2 \\
\hline & 1 & -0.43 & 1.31 & -0.01 & 0.04 & -3.44 & 40.73 & -0.22 & 1.12 & 89.7 \\
\hline Switzerland & 5 & 0.20 & 1.10 & -0.02 & -0.01 & 1.96 & 41.78 & -0.81 & -0.36 & 89.9 \\
\hline & $5-1$ & 0.63 & -0.20 & -0.01 & -0.05 & 3.53 & -4.44 & -0.32 & -0.99 & 10.0 \\
\hline & 1 & 0.09 & 0.84 & -0.10 & 0.01 & 0.61 & 27.51 & -3.46 & 0.16 & 75.5 \\
\hline UK & 5 & 0.72 & 0.79 & -0.08 & 0.07 & 5.06 & 27.02 & -3.01 & 1.31 & 74.9 \\
\hline & $5-1$ & 0.63 & -0.05 & 0.02 & 0.06 & 4.55 & -1.92 & 0.64 & 1.18 & 0.8 \\
\hline
\end{tabular}




\section{Table 6}

\section{Accounting for Multiple Testing}

The table gives the lower confidence band $c_{l}$ for the returns as obtained by the StepM method and the FDP$\mathrm{Step}_{0.1}$ using studentized test statistics as illustrated in Appendix 4.1. The rej-columns contain the resulting decision where 1 indicates rejection of $\theta_{s}=0$ (capital market efficiency). Panel A provides results for returns as test statistics and Panel B provides results for Fama-French alphas as test statistics.

\begin{tabular}{|c|c|c|c|c|c|c|c|c|c|c|}
\hline \multirow{3}{*}{ Country } & \multicolumn{5}{|c|}{ Price Momentum } & \multicolumn{5}{|c|}{ Earnings Momentum } \\
\hline & \multirow[t]{2}{*}{$\theta_{s}$} & \multicolumn{2}{|c|}{ StepM } & \multicolumn{2}{|c|}{$F D P-S t e p M_{0.1}$} & \multirow[t]{2}{*}{$\theta_{s}$} & \multicolumn{2}{|c|}{ StepM } & \multicolumn{2}{|c|}{ FDP-Step $M_{0.1}$} \\
\hline & & $c_{l}$ & $r e j$ & $c_{l}$ & $r e j$ & & $c_{l}$ & $r e j$ & $c_{l}$ & $r e j$ \\
\hline \multicolumn{11}{|c|}{ Panel A: Return } \\
\hline USA & 0.0072 & 0.0030 & 1 & 0.0044 & 1 & 0.0046 & 0.0005 & 1 & 0.0005 & 1 \\
\hline Europe & 0.0111 & 0.0061 & 1 & 0.0077 & 1 & 0.0076 & 0.0042 & 1 & 0.0042 & 1 \\
\hline Austria & 0.0063 & -0.0007 & 0 & 0.0016 & 1 & 0.0040 & -0.0047 & 0 & -0.0047 & 0 \\
\hline Belgium & 0.0094 & 0.0042 & 1 & 0.0059 & 1 & 0.0070 & 0.0020 & 1 & 0.0020 & 1 \\
\hline Denmark & 0.0095 & 0.0034 & 1 & 0.0055 & 1 & 0.0115 & 0.0039 & 1 & 0.0039 & 1 \\
\hline Finland & 0.0081 & 0.0004 & 1 & 0.0029 & 1 & 0.0085 & 0.0003 & 1 & 0.0003 & 1 \\
\hline France & 0.0096 & 0.0046 & 1 & 0.0063 & 1 & 0.0068 & 0.0024 & 1 & 0.0024 & 1 \\
\hline Germany & 0.0110 & 0.0053 & 1 & 0.0072 & 1 & 0.0076 & 0.0030 & 1 & 0.0030 & 1 \\
\hline Greece & 0.0122 & 0.0029 & 1 & 0.0060 & 1 & 0.0023 & -0.0076 & 0 & -0.0076 & 0 \\
\hline Ireland & 0.0068 & -0.0023 & 0 & 0.0007 & 1 & 0.0132 & -0.0013 & 0 & -0.0013 & 0 \\
\hline Italy & 0.0118 & 0.0064 & 1 & 0.0082 & 1 & 0.0026 & -0.0025 & 0 & -0.0025 & 0 \\
\hline Netherlands & 0.0071 & 0.0013 & 1 & 0.0032 & 1 & 0.0082 & 0.0014 & 1 & 0.0014 & 1 \\
\hline Norway & 0.0112 & 0.0035 & 1 & 0.0061 & 1 & 0.0061 & -0.0022 & 0 & -0.0022 & 0 \\
\hline Portugal & 0.0055 & -0.0024 & 0 & 0.0002 & 1 & 0.0081 & -0.0007 & 0 & -0.0007 & 0 \\
\hline Spain & 0.0080 & 0.0023 & 1 & 0.0042 & 1 & 0.0055 & -0.0015 & 0 & -0.0015 & 0 \\
\hline Sweden & 0.0053 & -0.0020 & 0 & 0.0005 & 1 & 0.0073 & 0.0002 & 1 & 0.0002 & 1 \\
\hline Switzerland & 0.0090 & 0.0022 & 1 & 0.0045 & 1 & 0.0053 & -0.0004 & 0 & -0.0004 & 0 \\
\hline UK & 0.0091 & 0.0031 & 1 & 0.0051 & 1 & 0.0063 & 0.0027 & 1 & 0.0027 & 1 \\
\hline \multicolumn{11}{|c|}{ Panel B: Fama-French Alpha } \\
\hline USA & 0.0083 & 0.0055 & 1 & 0.0064 & 1 & 0.0066 & 0.0036 & 1 & 0.0051 & 1 \\
\hline Europe & 0.0123 & 0.0088 & 1 & 0.0099 & 1 & 0.0084 & 0.0059 & 1 & 0.0072 & 1 \\
\hline Austria & 0.0067 & 0.0010 & 1 & 0.0028 & 1 & 0.0053 & -0.0015 & 0 & 0.0019 & 1 \\
\hline Belgium & 0.0104 & 0.0064 & 1 & 0.0077 & 1 & 0.0077 & 0.0037 & 1 & 0.0057 & 1 \\
\hline Denmark & 0.0102 & 0.0056 & 1 & 0.0071 & 1 & 0.0116 & 0.0051 & 1 & 0.0083 & 1 \\
\hline Finland & 0.0102 & 0.0044 & 1 & 0.0062 & 1 & 0.0097 & 0.0031 & 1 & 0.0064 & 1 \\
\hline France & 0.0122 & 0.0088 & 1 & 0.0099 & 1 & 0.0090 & 0.0055 & 1 & 0.0072 & 1 \\
\hline Germany & 0.0126 & 0.0083 & 1 & 0.0097 & 1 & 0.0083 & 0.0047 & 1 & 0.0065 & 1 \\
\hline Greece & 0.0127 & 0.0058 & 1 & 0.0080 & 1 & 0.0033 & -0.0045 & 0 & -0.0006 & 0 \\
\hline Ireland & 0.0067 & 0.0002 & 1 & 0.0023 & 1 & 0.0138 & 0.0022 & 1 & 0.0080 & 1 \\
\hline Italy & 0.0129 & 0.0087 & 1 & 0.0100 & 1 & 0.0031 & -0.0013 & 0 & 0.0009 & 1 \\
\hline Netherlands & 0.0085 & 0.0045 & 1 & 0.0058 & 1 & 0.0095 & 0.0041 & 1 & 0.0068 & 1 \\
\hline Norway & 0.0136 & 0.0077 & 1 & 0.0096 & 1 & 0.0080 & 0.0016 & 1 & 0.0048 & 1 \\
\hline Portugal & 0.0093 & 0.0029 & 1 & 0.0049 & 1 & 0.0089 & 0.0014 & 1 & 0.0051 & 1 \\
\hline Spain & 0.0089 & 0.0048 & 1 & 0.0061 & 1 & 0.0062 & 0.0007 & 1 & 0.0034 & 1 \\
\hline Sweden & 0.0069 & 0.0015 & 1 & 0.0032 & 1 & 0.0084 & 0.0026 & 1 & 0.0055 & 1 \\
\hline Switzerland & 0.0101 & 0.0052 & 1 & 0.0068 & 1 & 0.0063 & 0.0017 & 1 & 0.0040 & 1 \\
\hline UK & 0.0094 & 0.0049 & 1 & 0.0064 & 1 & 0.0063 & 0.0032 & 1 & 0.0047 & 1 \\
\hline \multirow{2}{*}{$\Sigma$} & & Return & 14 & & 18 & & & 10 & & 10 \\
\hline & & Alpha & 18 & & 18 & & & 15 & & 17 \\
\hline
\end{tabular}


Table 7

Time-Series-Regressions of Price Momentum Portfolios

The table's left panel gives the results of a regression according to equation (3) using 255 monthly returns ranging from January 1988 to March 2009 followed by the according $t$-statistics. The right panel gives the results of a regression according to equation (4). We use the country abbreviations introduced in Table 1 . We give the quintile portfolios 1 (loser) to 5 (winner) together with the long-short portfolio (winner-loser).

\begin{tabular}{|c|c|c|c|c|c|c|c|c|c|c|c|c|c|c|c|c|c|c|c|c|c|}
\hline & & \multicolumn{9}{|c|}{ Fama-French Model } & \multicolumn{11}{|c|}{ 4-Factor Model } \\
\hline & & $\alpha$ & $\beta$ & $\gamma$ & $\delta$ & $t(\alpha)$ & $t(\beta)$ & $t(\gamma)$ & $t(\delta)$ & $\begin{array}{r}\text { Adj. } \\
R^{2} \\
\end{array}$ & $\alpha$ & $\beta$ & $\gamma$ & $\delta$ & $\zeta$ & $t(\alpha)$ & $t(\beta)$ & $t(\gamma)$ & $t(\delta)$ & $t(\zeta)$ & $\begin{array}{r}\text { Adj. } \\
R^{2} \\
\end{array}$ \\
\hline \multirow{6}{*}{ USA } & 1 & -0.77 & 1.33 & -0.29 & 0.09 & -5.21 & 42.9 & -7.46 & 1.77 & 88.9 & -0.47 & 1.27 & -0.36 & 0.00 & -0.45 & -3.30 & 42.2 & -9.58 & -0.01 & -6.76 & 90.6 \\
\hline & 2 & -0.24 & 1.02 & -0.34 & 0.20 & -2.84 & 56.8 & -15.1 & 6.92 & 93.1 & -0.18 & 1.00 & -0.36 & 0.18 & -0.10 & -2.00 & 53.8 & -15.3 & 6.07 & -2.35 & 93.2 \\
\hline & 3 & -0.02 & 0.90 & -0.35 & 0.16 & -0.22 & 52.9 & -16.0 & 5.88 & 92.0 & -0.03 & 0.90 & -0.34 & 0.17 & 0.02 & -0.38 & 50.5 & -15.3 & 5.79 & 0.54 & 92.0 \\
\hline & 4 & 0.06 & 0.89 & -0.29 & 0.04 & 0.61 & 46.6 & -11.8 & 1.22 & 90.1 & -0.03 & 0.91 & -0.27 & 0.07 & 0.13 & -0.35 & 46.1 & -10.8 & 2.03 & 3.06 & 90.4 \\
\hline & 5 & 0.05 & 1.06 & -0.05 & -0.29 & 0.33 & 32.4 & -1.26 & -5.38 & 84.3 & -0.18 & 1.11 & 0.00 & -0.22 & 0.35 & -1.16 & 33.7 & -0.01 & -4.07 & 4.85 & 85.6 \\
\hline & $5-1$ & 0.83 & -0.27 & 0.24 & -0.38 & 3.70 & -5.84 & 4.08 & -4.94 & 19.7 & 0.29 & -0.16 & 0.36 & -0.22 & 0.80 & 1.40 & -3.73 & 6.62 & -3.08 & 8.35 & 37.0 \\
\hline \multirow{6}{*}{ EUR } & 1 & -0.63 & 1.27 & -0.35 & 0.28 & -5.16 & 42.3 & -7.92 & 4.62 & 88.6 & -0.06 & 1.15 & -0.35 & 0.21 & -0.69 & -0.47 & 40.1 & -9.10 & 3.91 & -9.45 & 91.6 \\
\hline & 2 & -0.19 & 1.00 & -0.36 & 0.26 & -2.52 & 54.8 & -13.4 & 7.10 & 93.0 & -0.11 & 0.98 & -0.36 & 0.25 & -0.10 & -1.24 & 48.7 & -13.4 & 6.78 & -1.91 & 93.1 \\
\hline & 3 & 0.09 & 0.92 & -0.36 & 0.16 & 1.35 & 54.0 & -14.4 & 4.58 & 92.7 & -0.01 & 0.94 & -0.36 & 0.17 & 0.12 & -0.07 & 50.1 & -14.6 & 4.95 & 2.50 & 92.8 \\
\hline & 4 & 0.28 & 0.94 & -0.33 & 0.05 & 3.54 & 49.0 & -11.9 & 1.17 & 91.0 & 0.04 & 0.98 & -0.34 & 0.08 & 0.28 & 0.50 & 48.9 & -12.6 & 2.03 & 5.47 & 91.9 \\
\hline & 5 & 0.60 & 1.06 & -0.26 & -0.03 & 4.90 & 35.5 & -5.9 & -0.56 & 83.7 & 0.19 & 1.15 & -0.26 & 0.02 & 0.49 & 1.41 & 37.0 & -6.4 & 0.35 & 6.29 & 85.9 \\
\hline & $5-1$ & 1.23 & -0.21 & 0.09 & -0.32 & 6.43 & -4.45 & 1.33 & -3.31 & 12.5 & 0.24 & 0.00 & 0.08 & -0.19 & 1.18 & 1.33 & -0.09 & 1.48 & -2.36 & 10.8 & 40.3 \\
\hline A & $5-1$ & 0.67 & 0.04 & 0.00 & -0.13 & 2.09 & 0.48 & 0.05 & -2.14 & 0.6 & 0.47 & 0.14 & -0.06 & -0.11 & 0.38 & 1.52 & 1.93 & -0.82 & -1.86 & 5.37 & 10.6 \\
\hline BEL & $5-1$ & 1.04 & -0.13 & 0.01 & -0.15 & 4.52 & -2.09 & 0.35 & -2.87 & 4.6 & 0.61 & -0.06 & 0.02 & -0.11 & 0.55 & 2.86 & -1.14 & 0.62 & -2.20 & 7.75 & 22.8 \\
\hline DK & $5-1$ & 1.02 & -0.23 & 0.03 & -0.06 & 3.91 & -3.69 & 0.44 & -1.27 & 4.9 & 0.57 & -0.20 & 0.06 & -0.03 & 0.40 & 2.28 & -3.36 & 0.94 & -0.67 & 6.99 & 20.2 \\
\hline $\mathrm{FN}$ & $5-1$ & 1.02 & -0.28 & -0.16 & -0.02 & 2.72 & -4.64 & -2.07 & -0.47 & 7.6 & 0.39 & -0.14 & -0.13 & 0.01 & 0.66 & 1.19 & -2.57 & -1.96 & 0.22 & 9.28 & 32.8 \\
\hline FR & $5-1$ & 1.22 & -0.26 & -0.06 & -0.27 & 5.42 & -5.56 & -0.95 & -5.02 & 18.1 & 0.51 & -0.09 & -0.11 & -0.13 & 0.79 & 2.55 & -2.14 & -1.97 & -2.76 & 10.4 & 42.6 \\
\hline GER & $5-1$ & 1.26 & -0.47 & 0.08 & -0.05 & 4.86 & -7.56 & 1.20 & -0.74 & 18.3 & 0.56 & -0.36 & 0.11 & 0.03 & 0.84 & 2.29 & -6.40 & 1.89 & 0.46 & 8.25 & 35.6 \\
\hline GR & $5-1$ & 1.27 & 0.07 & -0.14 & -0.25 & 2.60 & 1.57 & -1.13 & -1.64 & 1.8 & 1.19 & 0.08 & -0.15 & -0.24 & 0.18 & 2.43 & 1.88 & -1.23 & -1.52 & 1.61 & 2.7 \\
\hline IRL & $5-1$ & 0.67 & -0.06 & -0.03 & -0.26 & 1.64 & -0.83 & -0.47 & -4.74 & 10.0 & 0.19 & -0.01 & -0.04 & -0.31 & 0.26 & 0.44 & -0.18 & -0.74 & -5.49 & 3.60 & 22.6 \\
\hline IL & $5-1$ & 1.29 & -0.22 & 0.14 & -0.14 & 4.98 & -5.26 & 2.11 & -2.20 & 11.3 & 1.16 & -0.17 & 0.10 & -0.13 & 0.37 & 4.64 & -4.21 & 1.61 & -2.10 & 4.67 & 18.1 \\
\hline NL & $5-1$ & 0.85 & -0.08 & -0.03 & -0.21 & 3.46 & -1.41 & -0.73 & -3.91 & 8.8 & 0.18 & 0.00 & 0.00 & -0.10 & 0.70 & 0.85 & -0.10 & 0.06 & -2.24 & 11.3 & 39.6 \\
\hline NOR & $5-1$ & 1.36 & -0.14 & 0.20 & -0.18 & 3.78 & -2.53 & 1.91 & -2.45 & 5.0 & 1.08 & -0.07 & 0.22 & -0.16 & 0.34 & 3.08 & -1.32 & 2.17 & -2.25 & 4.77 & 12.7 \\
\hline POR & $5-1$ & 0.93 & -0.23 & -0.21 & -0.09 & 2.11 & -2.69 & -1.57 & -0.89 & 3.6 & 0.48 & -0.20 & -0.08 & -0.12 & 0.43 & 1.15 & -2.47 & -0.63 & -1.28 & 5.36 & 15.9 \\
\hline ES & $5-1$ & 0.89 & -0.22 & 0.00 & -0.01 & 3.64 & -5.06 & 0.07 & -0.17 & 8.4 & 0.58 & -0.12 & 0.00 & -0.02 & 0.50 & 2.59 & -2.90 & -0.03 & -0.47 & 8.00 & 26.9 \\
\hline SWE & $5-1$ & 0.69 & -0.22 & 0.00 & -0.03 & 2.31 & -5.07 & -0.07 & -0.72 & 8.3 & 0.40 & -0.17 & 0.00 & -0.02 & 0.34 & 1.37 & -4.04 & 0.00 & -0.46 & 4.83 & 15.8 \\
\hline $\mathrm{CH}$ & $5-1$ & 1.01 & -0.14 & 0.08 & -0.16 & 4.10 & -2.19 & 1.22 & -2.59 & 8.4 & 0.55 & 0.01 & 0.09 & -0.13 & 0.74 & 2.58 & 0.20 & 1.62 & -2.43 & 9.97 & 34.3 \\
\hline UK & $5-1$ & 0.94 & -0.04 & 0.07 & -0.43 & 4.04 & -0.77 & 1.61 & -4.99 & 9.9 & 0.63 & -0.01 & 0.06 & -0.46 & 0.49 & 2.72 & -0.24 & 1.45 & -5.55 & 4.77 & 17.1 \\
\hline
\end{tabular}


Table 8

Time-Series-Regressions of Earnings Momentum Portfolios

The table's left panel gives the results of a regression according to equation (3) using 255 monthly returns ranging from January 1988 to March 2009 followed by the according $t$-statistics. The right panel gives the results of a regression according to equation (5). We use the country abbreviations introduced in Table 1 . We give the quintile portfolios 1 (negative earnings revisions) to 5 (positive earnings revisions) together with the long-short portfolio (positive-negative earnings revisions).

\begin{tabular}{|c|c|c|c|c|c|c|c|c|c|c|c|c|c|c|c|c|c|c|c|c|c|}
\hline & & \multicolumn{9}{|c|}{ Fama-French Model } & \multicolumn{11}{|c|}{ 4-Factor Model } \\
\hline & & $\alpha$ & $\beta$ & $\gamma$ & $\delta$ & $t(\alpha)$ & $t(\beta)$ & $t(\gamma)$ & $t(\delta)$ & $\begin{array}{r}\text { Adj. } \\
R^{2} \\
\end{array}$ & $\alpha$ & $\beta$ & $\gamma$ & $\delta$ & $\zeta$ & $t(\alpha)$ & $t(\beta)$ & $t(\gamma)$ & $t(\delta)$ & $t(\zeta)$ & $\begin{array}{r}\text { Adj. } \\
R^{2}\end{array}$ \\
\hline \multirow{6}{*}{ USA } & 1 & -0.59 & 1.23 & -0.09 & 0.14 & -5.25 & 52.2 & -3.16 & 3.73 & 92.8 & -0.52 & 1.21 & -0.08 & 0.12 & -0.08 & -4.54 & 48.5 & -2.47 & 2.96 & -2.50 & 93.0 \\
\hline & 2 & -0.41 & 1.03 & -0.23 & 0.10 & -4.32 & 53.0 & -9.32 & 3.04 & 92.4 & -0.38 & 1.03 & -0.23 & 0.10 & -0.02 & -3.98 & 49.7 & -8.92 & 2.98 & -0.65 & 92.5 \\
\hline & 3 & -0.26 & 0.92 & -0.34 & 0.03 & -2.97 & 51.2 & -14.8 & 1.06 & 91.5 & -0.31 & 0.94 & -0.35 & 0.05 & 0.06 & -3.49 & 49.4 & -15.1 & 1.76 & 2.48 & 91.7 \\
\hline & 4 & -0.05 & 0.94 & -0.33 & -0.16 & -0.49 & 46.4 & -12.6 & -4.85 & 90.0 & -0.13 & 0.98 & -0.35 & -0.11 & 0.11 & -1.37 & 46.2 & -13.6 & -3.35 & 4.09 & 90.6 \\
\hline & 5 & 0.07 & 1.09 & -0.24 & -0.06 & 0.66 & 48.4 & -8.5 & -1.76 & 91.1 & -0.08 & 1.14 & -0.29 & 0.02 & 0.19 & -0.78 & 52.4 & -10.8 & 0.58 & 7.00 & 92.7 \\
\hline & $5-1$ & 0.66 & -0.14 & -0.15 & -0.21 & 5.09 & -5.16 & -4.26 & -4.68 & 26.7 & 0.44 & -0.06 & -0.21 & -0.10 & 0.27 & 3.73 & -2.49 & -6.75 & -2.36 & 8.35 & 42.0 \\
\hline \multirow{6}{*}{ EUR } & 1 & -0.40 & 1.20 & -0.25 & 0.23 & -4.52 & 55.1 & -7.76 & 5.14 & 92.8 & -0.25 & 1.18 & -0.23 & 0.19 & -0.12 & -2.68 & 53.9 & -7.49 & 4.42 & -4.15 & 93.4 \\
\hline & 2 & -0.22 & 1.08 & -0.36 & 0.09 & -3.45 & 69.1 & -15.6 & 2.94 & 95.3 & -0.17 & 1.08 & -0.36 & 0.08 & -0.04 & -2.48 & 66.2 & -15.4 & 2.50 & -1.88 & 95.3 \\
\hline & 3 & -0.04 & 0.97 & -0.38 & 0.02 & -0.59 & 63.4 & -16.8 & 0.54 & 94.4 & -0.05 & 0.98 & -0.38 & 0.02 & 0.01 & -0.74 & 61.2 & -16.8 & 0.63 & 0.52 & 94.4 \\
\hline & 4 & 0.09 & 0.96 & -0.37 & -0.01 & 1.32 & 54.8 & -14.2 & -0.29 & 92.6 & -0.04 & 0.99 & -0.38 & 0.02 & 0.11 & -0.58 & 56.3 & -15.2 & 0.67 & 4.80 & 93.2 \\
\hline & 5 & 0.44 & 1.03 & -0.24 & 0.12 & 5.21 & 49.9 & -7.93 & 2.88 & 91.3 & 0.26 & 1.06 & -0.25 & 0.17 & 0.15 & 2.98 & 52.8 & -8.79 & 4.24 & 5.87 & 92.3 \\
\hline & $5-1$ & 0.84 & -0.17 & 0.01 & -0.11 & 9.19 & -7.70 & 0.26 & -2.35 & 22.1 & 0.50 & -0.12 & -0.02 & -0.02 & 0.27 & 6.15 & -6.05 & -0.68 & -0.59 & 10.8 & 46.9 \\
\hline A & $5-1$ & 0.53 & -0.28 & 0.17 & -0.06 & 1.96 & -4.43 & 2.60 & -1.16 & 8.8 & 0.35 & -0.29 & 0.17 & -0.02 & 0.27 & 1.35 & -4.82 & 2.73 & -0.49 & 5.37 & 17.9 \\
\hline BEL & $5-1$ & 0.77 & -0.12 & -0.01 & -0.08 & 4.21 & -2.41 & -0.49 & -2.00 & 3.5 & 0.40 & -0.07 & -0.02 & -0.03 & 0.35 & 2.36 & -1.62 & -0.71 & -0.79 & 7.75 & 21.9 \\
\hline DK & $5-1$ & 1.16 & -0.10 & -0.08 & -0.08 & 4.35 & -1.48 & -1.04 & -1.63 & 1.3 & 0.73 & 0.00 & -0.09 & -0.06 & 0.41 & 2.88 & 0.01 & -1.34 & -1.22 & 6.99 & 17.2 \\
\hline $\mathrm{FN}$ & $5-1$ & 0.97 & -0.22 & -0.05 & -0.04 & 3.33 & -4.59 & -0.88 & -1.24 & 7.8 & 0.53 & -0.10 & 0.02 & -0.03 & 0.42 & 2.04 & -2.29 & 0.38 & -1.19 & 9.28 & 33.0 \\
\hline $\mathrm{FR}$ & $5-1$ & 0.90 & -0.22 & 0.06 & -0.18 & 5.79 & -6.68 & 1.28 & -4.75 & 20.9 & 0.43 & -0.12 & 0.09 & -0.07 & 0.38 & 3.12 & -3.99 & 2.16 & -2.27 & 10.4 & 44.4 \\
\hline GER & $5-1$ & 0.83 & -0.12 & -0.04 & -0.09 & 5.73 & -3.62 & -1.07 & -2.47 & 5.5 & 0.51 & -0.01 & -0.06 & -0.08 & 0.26 & 3.84 & -0.21 & -1.80 & -2.41 & 8.25 & 25.7 \\
\hline GR & $5-1$ & 0.33 & -0.08 & 0.05 & -0.10 & 1.03 & -2.65 & 0.66 & -1.00 & 3.5 & 0.34 & -0.09 & 0.07 & -0.09 & 0.08 & 1.03 & -3.01 & 0.91 & -0.83 & 1.61 & 5.1 \\
\hline IRL & $5-1$ & 1.38 & -0.12 & -0.06 & -0.12 & 3.02 & -1.42 & -1.00 & -1.89 & 2.9 & 1.27 & -0.10 & -0.04 & -0.02 & 0.28 & 2.86 & -1.29 & -0.74 & -0.28 & 3.60 & 9.1 \\
\hline IL & $5-1$ & 0.31 & -0.12 & 0.09 & -0.03 & 1.58 & -3.85 & 1.86 & -0.63 & 5.5 & 0.06 & -0.08 & 0.07 & 0.00 & 0.22 & 0.31 & -2.34 & 1.39 & -0.02 & 4.67 & 13.0 \\
\hline NL & $5-1$ & 0.95 & -0.11 & -0.05 & -0.15 & 4.60 & -2.43 & -1.33 & -3.42 & 10.2 & 0.55 & -0.07 & -0.03 & -0.06 & 0.49 & 3.20 & -1.78 & -1.11 & -1.45 & 11.3 & 40.5 \\
\hline NOR & $5-1$ & 0.80 & -0.20 & -0.05 & -0.07 & 2.61 & -4.20 & -0.56 & -1.05 & 6.9 & 0.47 & -0.17 & -0.10 & -0.02 & 0.25 & 1.54 & -3.57 & -1.15 & -0.35 & 4.77 & 14.3 \\
\hline POR & $5-1$ & 0.89 & -0.06 & -0.29 & 0.08 & 2.40 & -0.85 & -2.55 & 0.95 & 2.1 & 0.76 & 0.00 & -0.24 & 0.10 & 0.31 & 2.12 & -0.06 & -2.22 & 1.24 & 5.36 & 15.0 \\
\hline $\mathrm{ES}$ & $5-1$ & 0.62 & -0.20 & 0.01 & 0.03 & 2.75 & -5.19 & 0.11 & 0.54 & 9.1 & 0.25 & -0.11 & 0.00 & 0.03 & 0.41 & 1.23 & -3.08 & 0.11 & 0.70 & 8.00 & 27.5 \\
\hline SWE & $5-1$ & 0.84 & -0.14 & -0.01 & -0.04 & 3.30 & -3.75 & -0.24 & -0.95 & 4.2 & 0.67 & -0.08 & -0.01 & -0.03 & 0.25 & 2.71 & -2.22 & -0.23 & -0.77 & 4.83 & 12.0 \\
\hline $\mathrm{CH}$ & $5-1$ & 0.63 & -0.20 & -0.01 & -0.05 & 3.53 & -4.44 & -0.32 & -0.99 & 10.0 & 0.23 & -0.15 & -0.04 & 0.02 & 0.39 & 1.47 & -3.81 & -1.10 & 0.46 & 9.97 & 35.4 \\
\hline UK & $5-1$ & 0.63 & -0.05 & 0.02 & 0.06 & 4.55 & -1.92 & 0.64 & 1.18 & 0.8 & 0.47 & -0.05 & 0.01 & 0.13 & 0.17 & 3.45 & -1.71 & 0.29 & 2.61 & 4.77 & 8.7 \\
\hline
\end{tabular}


Table 9

\section{Momentum and Information Uncertainty}

The table gives return differentials of the price and earnings momentum hedge strategies by terciles of different information uncertainty metrics. In Panel A we first sort stocks into five quintiles based on past returns. For each quintile the stocks are further sorted into three terciles based on analyst coverage, size, total stock volatility and idiosyncratic volatility. Below the return differentials we give $t$-statistics. The last two rows collect the number of countries that exhibit the highest return differential among the respective terciles and the terciles mean ranking in terms of returns. Panel B gives analogous results for earnings momentum.

\begin{tabular}{|c|c|c|c|c|c|c|c|c|c|c|c|c|}
\hline \multirow{2}{*}{ Country } & \multicolumn{3}{|c|}{ Analyst Coverage } & \multicolumn{3}{|c|}{ Size } & \multicolumn{3}{|c|}{ Volatility } & \multicolumn{3}{|c|}{ Idiosyncratic } \\
\hline & Low & Mid & High & Low & Mid & High & Low & Mid & High & Low & Mid & High \\
\hline \multicolumn{13}{|c|}{ Panel A: Price Momentum } \\
\hline \multirow{2}{*}{ USA } & 1.05 & 0.70 & 0.56 & 1.15 & 0.68 & 0.60 & 0.65 & 0.72 & 0.77 & 0.72 & 0.75 & 0.71 \\
\hline & 4.79 & 3.03 & 1.86 & 5.01 & 2.92 & 1.98 & 3.63 & 3.76 & 3.12 & 3.68 & 3.60 & 2.96 \\
\hline \multirow{2}{*}{ Europe } & 1.21 & 1.34 & 0.77 & 1.72 & 1.07 & 0.87 & 1.15 & 1.01 & 1.21 & 1.06 & 1.00 & 1.17 \\
\hline & 4.77 & 6.29 & 3.40 & 5.93 & 4.81 & 3.65 & 6.84 & 5.93 & 4.97 & 5.67 & 5.56 & 5.00 \\
\hline \multirow{2}{*}{ Denmark } & -0.30 & 1.05 & 0.72 & -0.17 & 1.08 & 1.07 & 0.97 & 1.01 & 0.63 & 0.91 & 0.84 & 0.91 \\
\hline & -0.60 & 3.15 & 2.01 & -0.34 & 2.42 & 3.36 & 2.84 & 2.98 & 1.59 & 2.96 & 2.74 & 2.38 \\
\hline \multirow{2}{*}{ France } & 0.88 & 1.21 & 0.57 & 1.19 & 1.00 & 0.74 & 0.85 & 1.21 & 0.93 & 0.86 & 1.02 & 1.28 \\
\hline & 2.80 & 4.07 & 1.95 & 3.27 & 3.52 & 2.54 & 3.49 & 5.16 & 2.91 & 3.05 & 4.02 & 3.99 \\
\hline \multirow{2}{*}{ Germany } & 0.77 & 1.63 & 0.94 & 1.11 & 1.29 & 0.66 & 0.69 & 0.99 & 0.99 & 0.98 & 0.99 & 1.13 \\
\hline & 2.00 & 5.62 & 2.69 & 2.95 & 3.56 & 2.11 & 3.31 & 3.72 & 2.94 & 4.30 & 3.39 & 3.23 \\
\hline \multirow{2}{*}{ Italy } & 1.52 & 2.16 & 0.86 & 2.24 & 1.66 & 0.68 & 1.11 & 1.07 & 2.03 & 0.96 & 0.49 & 1.95 \\
\hline & 3.53 & 5.51 & 2.47 & 6.15 & 4.59 & 1.89 & 4.36 & 3.06 & 5.20 & 3.07 & 1.39 & 5.25 \\
\hline \multirow{2}{*}{ Netherlands } & 0.93 & 0.83 & 0.29 & 0.76 & 1.10 & 0.09 & 0.88 & 0.84 & 0.72 & 0.93 & 0.48 & 1.04 \\
\hline & 2.83 & 2.40 & 0.85 & 2.09 & 3.30 & 0.26 & 2.54 & 2.80 & 2.15 & 3.05 & 1.65 & 3.08 \\
\hline \multirow{2}{*}{ Spain } & 1.01 & 0.81 & 0.75 & 1.68 & 0.68 & 0.27 & 0.35 & 0.74 & 1.12 & 0.19 & 1.05 & 1.05 \\
\hline & 2.86 & 2.30 & 2.34 & 4.46 & 1.91 & 0.88 & 0.97 & 2.37 & 3.33 & 0.51 & 3.71 & 3.00 \\
\hline \multirow{2}{*}{ Sweden } & 1.57 & 0.75 & -0.03 & 1.41 & 0.23 & 0.03 & 0.52 & 0.21 & 0.03 & -0.17 & 0.21 & 1.14 \\
\hline & 3.78 & 2.16 & -0.07 & 3.28 & 0.54 & 0.07 & 1.53 & 0.54 & 0.06 & -0.41 & 0.57 & 2.80 \\
\hline \multirow{2}{*}{ Switzerland } & 0.98 & 1.06 & 0.89 & 0.95 & 0.87 & 0.84 & 1.66 & 0.87 & 1.15 & 1.48 & 0.76 & 0.90 \\
\hline & 2.47 & 3.62 & 3.04 & 2.50 & 2.70 & 2.71 & 5.15 & 3.44 & 3.43 & 3.89 & 3.04 & 2.79 \\
\hline \multirow{2}{*}{ UK } & 1.20 & 1.13 & 0.52 & 1.38 & 1.10 & 0.50 & 0.76 & 0.87 & 0.97 & 0.67 & 0.89 & 0.98 \\
\hline & 4.38 & 3.84 & 1.75 & 4.57 & 4.34 & 1.64 & 3.37 & 3.44 & 3.53 & 2.82 & 3.62 & 3.37 \\
\hline$\# \max$ & 5 & 6 & 0 & 8 & 3 & 0 & 3 & 2 & 6 & 1 & 1 & 9 \\
\hline ranking & 1.73 & 1.45 & 2.82 & 1.36 & 1.73 & 2.91 & 2.18 & 2.00 & 1.73 & 2.27 & 2.27 & 1.27 \\
\hline Panel B: Ea & s $M o m$ & ntum & & & & & & & & & & \\
\hline USA & 0.77 & 0.48 & 0.20 & 0.78 & 0.49 & 0.27 & 0.59 & 0.58 & 0.41 & 0.59 & 0.50 & 0.47 \\
\hline USA & 5.24 & 3.03 & 0.95 & 4.76 & 3.13 & 1.40 & 4.44 & 3.60 & 2.36 & 4.04 & 3.10 & 2.75 \\
\hline Furone & 0.85 & 0.85 & 0.59 & 1.11 & 0.64 & 0.63 & 0.69 & 0.73 & 0.75 & 0.72 & 0.77 & 0.77 \\
\hline & 7.13 & 6.76 & 3.75 & 8.39 & 5.74 & 4.04 & 6.64 & 7.53 & 5.25 & 6.99 & 7.51 & 5.52 \\
\hline Denmark & 1.39 & 1.22 & 0.77 & 1.07 & 1.30 & 0.79 & 2.19 & 1.07 & 0.74 & 1.42 & 1.27 & 0.83 \\
\hline Denmark & 3.06 & 2.40 & 2.00 & 1.43 & 3.88 & 2.65 & 2.18 & 3.73 & 1.84 & 2.33 & 4.44 & 2.15 \\
\hline France & 0.42 & 0.69 & 0.72 & 0.53 & 0.58 & 0.75 & 0.69 & 0.50 & 0.67 & 0.76 & 0.81 & 0.58 \\
\hline France & 1.86 & 2.82 & 2.75 & 1.85 & 2.45 & 3.15 & 3.46 & 2.36 & 2.44 & 3.79 & 3.67 & 2.08 \\
\hline Germany & 0.65 & 0.99 & 0.60 & 1.20 & 0.78 & 0.35 & 0.77 & 0.85 & 0.56 & 0.75 & 0.81 & 0.71 \\
\hline Germany & 2.64 & 4.65 & 2.37 & 4.28 & 3.62 & 1.65 & 3.79 & 4.95 & 2.20 & 4.06 & 4.36 & 2.66 \\
\hline Italy & 0.18 & 0.53 & 0.25 & -0.12 & 0.06 & 0.36 & 0.01 & -0.01 & 0.35 & 0.05 & 0.66 & 0.05 \\
\hline Italy & 0.62 & 1.55 & 0.88 & -0.40 & 0.19 & 1.26 & 0.02 & -0.03 & 1.01 & 0.22 & 2.50 & 0.12 \\
\hline Netherlands & 1.15 & 1.31 & 0.04 & 1.34 & 0.97 & 0.21 & 0.86 & 0.44 & 0.89 & 0.48 & 0.41 & 1.30 \\
\hline Netherlands & 4.14 & 4.38 & 0.12 & 4.56 & 3.25 & 0.53 & 3.04 & 1.62 & 2.61 & 1.91 & 1.59 & 3.84 \\
\hline Snain & 0.72 & 0.57 & 0.14 & 1.00 & 0.07 & 0.60 & 0.25 & 0.41 & 0.74 & 0.32 & 0.19 & 0.79 \\
\hline Spain & 2.22 & 1.69 & 0.39 & 3.05 & 0.22 & 1.67 & 1.01 & 1.27 & 2.32 & 1.03 & 0.63 & 2.33 \\
\hline Sweden & 0.69 & 1.02 & 0.57 & 0.74 & 1.46 & 0.00 & 0.79 & 0.86 & 0.87 & 0.69 & 0.54 & 1.25 \\
\hline & 2.08 & 3.02 & 1.43 & 2.08 & 4.45 & 0.00 & 2.80 & 2.48 & 2.17 & 2.24 & 1.74 & 3.18 \\
\hline Switzerland & 0.60 & 0.80 & 0.50 & 0.90 & 0.41 & 0.80 & 0.26 & 0.51 & 0.56 & 0.70 & 0.40 & 0.48 \\
\hline Switzerland & 2.20 & 3.05 & 1.70 & 3.07 & 1.75 & 2.64 & 1.19 & 2.21 & 1.91 & 2.99 & 1.81 & 1.55 \\
\hline UKK & 1.01 & 0.55 & 0.31 & 1.29 & 0.62 & 0.33 & 0.42 & 0.78 & 0.80 & 0.46 & 0.69 & 0.86 \\
\hline UK & 4.98 & 2.53 & 1.65 & 5.53 & 2.97 & 1.72 & 2.55 & 4.42 & 3.45 & 3.01 & 3.89 & 3.73 \\
\hline$\# \max$ & 5 & 5 & 1 & 7 & 2 & 2 & 3 & 1 & 7 & 3 & 3 & 5 \\
\hline ranking & 1.73 & 1.45 & 2.73 & 1.55 & 2.00 & 2.45 & 2.18 & 2.18 & 1.64 & 1.91 & 2.00 & 1.91 \\
\hline
\end{tabular}


Table 10

Momentum and Liquidity

The table gives return differentials of the price and earnings momentum hedge strategies by terciles of different liquidity metrics. In Panel A we first sort stocks into five quintiles based on past returns. For each quintile the stocks are further sorted into three terciles based on dollar volume, share turnover, the ILLIQ measure of Amihud, and Liu's measure. Below the return differentials we give $t$-statistics. The two last rows collect the number of countries that exhibit the highest return differential among the respective terciles and the terciles mean ranking in terms of returns. Panel B gives analogous results for earnings momentum.

\begin{tabular}{|c|c|c|c|c|c|c|c|c|c|c|c|c|}
\hline \multirow{2}{*}{ Country } & \multicolumn{3}{|c|}{ Dollar Volume } & \multicolumn{3}{|c|}{ Share Turnover } & \multicolumn{3}{|c|}{$I L L I Q$} & \multicolumn{3}{|c|}{ Liu Measure } \\
\hline & High & Mid & Low & High & Mid & Low & Low & Mid & High & Low & Mid & High \\
\hline \multicolumn{13}{|c|}{ Panel A: Price Momentum } \\
\hline \multirow{2}{*}{ USA } & 0.57 & 0.66 & 0.82 & 0.62 & 0.58 & 0.69 & 0.62 & 0.64 & 1.08 & 0.62 & 0.50 & 1.11 \\
\hline & 1.91 & 2.86 & 4.09 & 2.29 & 2.61 & 3.63 & 2.11 & 2.71 & 4.65 & 2.37 & 2.18 & 5.03 \\
\hline \multirow{2}{*}{ Europe } & 0.99 & 1.18 & 1.29 & 1.22 & 0.98 & 1.07 & 0.96 & 1.22 & 1.24 & 1.19 & 0.97 & 1.37 \\
\hline & 4.10 & 5.79 & 7.11 & 5.03 & 4.93 & 5.94 & 4.06 & 5.51 & 7.00 & 5.16 & 4.46 & 7.70 \\
\hline \multirow{2}{*}{ Denmark } & 0.81 & 0.81 & 0.47 & 1.08 & 0.61 & 0.93 & 0.95 & 0.84 & 0.74 & 1.05 & 0.85 & 0.13 \\
\hline & 2.57 & 2.23 & 1.25 & 3.08 & 1.79 & 2.57 & 3.13 & 2.15 & 1.62 & 3.18 & 1.90 & 0.26 \\
\hline \multirow{2}{*}{ France } & 0.69 & 1.05 & 1.28 & 0.80 & 0.97 & 1.11 & 0.76 & 1.10 & 1.13 & 0.77 & 1.10 & 1.15 \\
\hline & 2.43 & 3.92 & 4.00 & 2.93 & 3.45 & 4.09 & 2.72 & 3.95 & 3.75 & 2.81 & 3.94 & 4.03 \\
\hline \multirow{2}{*}{ Germany } & 1.11 & 0.98 & 1.31 & 1.31 & 0.81 & 1.14 & 1.07 & 1.06 & 1.24 & 1.18 & 1.01 & 0.92 \\
\hline & 3.44 & 3.16 & 3.95 & 4.09 & 2.67 & 4.17 & 3.13 & 3.15 & 4.07 & 3.68 & 3.46 & 4.06 \\
\hline \multirow{2}{*}{ Italy } & 1.13 & 1.34 & 0.65 & 1.34 & 1.04 & 0.95 & 0.96 & 1.23 & 1.16 & 1.28 & 1.07 & 0.74 \\
\hline & 2.98 & 3.78 & 2.02 & 3.69 & 3.02 & 2.94 & 2.88 & 3.64 & 3.85 & 3.71 & 3.57 & 1.66 \\
\hline \multirow{2}{*}{ Netherlands } & 0.25 & 1.09 & 0.52 & 0.59 & 0.59 & 0.86 & 0.24 & 1.09 & 0.85 & 0.30 & 0.88 & 1.09 \\
\hline & 0.74 & 3.19 & 1.49 & 1.83 & 1.77 & 2.48 & 0.68 & 3.19 & 2.41 & 0.88 & 2.67 & 3.36 \\
\hline \multirow{2}{*}{ Spain } & 0.65 & 0.43 & 0.88 & 0.68 & 1.04 & 0.18 & 0.54 & 0.68 & 0.77 & 0.79 & 0.68 & 0.41 \\
\hline & 2.05 & 1.41 & 2.78 & 2.12 & 3.46 & 0.56 & 1.78 & 2.10 & 2.07 & 2.50 & 2.33 & 1.07 \\
\hline \multirow{2}{*}{ Sweden } & 0.14 & 0.28 & 0.86 & 0.15 & 0.23 & -0.58 & 0.04 & 0.27 & 0.54 & -0.10 & 0.61 & 0.02 \\
\hline & 0.36 & 0.63 & 2.24 & 0.33 & 0.59 & -1.30 & 0.09 & 0.67 & 1.43 & -0.26 & 1.45 & 0.04 \\
\hline \multirow{2}{*}{ Switzerland } & 1.06 & 0.61 & 0.88 & 1.06 & 0.89 & 0.57 & 0.87 & 0.63 & 1.06 & 1.06 & 0.54 & 1.10 \\
\hline & 3.16 & 2.02 & 2.66 & 3.14 & 2.99 & 2.07 & 2.42 & 1.99 & 3.38 & 3.20 & 1.87 & 2.83 \\
\hline \multirow{2}{*}{ UK } & 1.00 & 1.15 & 0.96 & 1.13 & 0.99 & 0.99 & 1.03 & 1.00 & 1.05 & 1.01 & 1.06 & 1.12 \\
\hline & 3.45 & 4.33 & 4.06 & 4.20 & 4.03 & 3.85 & 3.74 & 3.51 & 4.41 & 3.71 & 4.32 & 4.37 \\
\hline$\# \max$ & 1 & 4 & 6 & 6 & 2 & 3 & 1 & 2 & 8 & 4 & 1 & 6 \\
\hline ranking & 2.27 & 1.91 & 1.73 & 1.55 & 2.18 & 2.09 & 2.55 & 2.09 & 1.36 & 2.00 & 2.18 & 1.82 \\
\hline Panel B: Ea & Mome & tum & & & & & & & & & & \\
\hline USA & 0.29 & 0.32 & 0.83 & 0.16 & 0.48 & 0.75 & 0.23 & 0.39 & 0.86 & 0.25 & 0.38 & 0.88 \\
\hline USA & 1.46 & 1.93 & 5.26 & 0.83 & 2.85 & 5.21 & 1.20 & 2.30 & 5.36 & 1.33 & 2.22 & 6.60 \\
\hline Europe & 0.66 & 0.79 & 0.83 & 0.85 & 0.65 & 0.81 & 0.67 & 0.78 & 0.83 & 0.76 & 0.76 & 0.84 \\
\hline Lurope & 4.28 & 6.71 & 8.02 & 6.01 & 5.36 & 8.37 & 4.53 & 6.81 & 7.50 & 4.93 & 7.02 & 8.78 \\
\hline Denmark & 0.95 & 1.88 & 1.73 & 1.00 & 1.66 & 2.06 & 1.23 & 1.56 & 2.50 & 1.23 & 1.85 & 2.08 \\
\hline 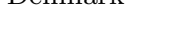 & 2.17 & 3.84 & 2.23 & 2.32 & 3.35 & 2.55 & 2.78 & 2.99 & 3.98 & 2.20 & 3.66 & 3.09 \\
\hline France & 0.52 & 0.71 & 0.47 & 0.67 & 0.52 & 0.62 & 0.63 & 0.70 & 0.47 & 0.58 & 0.78 & 0.49 \\
\hline & 2.16 & 3.24 & 1.92 & 2.58 & 2.56 & 3.04 & 2.62 & 3.15 & 2.10 & 2.40 & 3.63 & 2.32 \\
\hline Germany & 0.70 & 0.87 & 0.78 & 0.79 & 0.60 & 0.86 & 0.68 & 0.63 & 0.99 & 0.70 & 0.80 & 0.77 \\
\hline & 3.34 & 4.75 & 3.64 & 3.73 & 3.57 & 4.33 & 3.25 & 3.49 & 4.55 & 3.50 & 4.72 & 3.60 \\
\hline Italy & 0.52 & 0.25 & -0.43 & 0.58 & 0.01 & -0.04 & 0.45 & 0.28 & -0.24 & 0.45 & 0.14 & 0.09 \\
\hline lidaly & 1.93 & 0.91 & -1.49 & 1.91 & 0.03 & -0.16 & 1.75 & 1.09 & -0.76 & 1.54 & 0.52 & 0.31 \\
\hline Netherlands & 0.25 & 0.68 & 1.42 & 0.71 & 0.35 & 1.22 & 0.27 & 0.64 & 1.21 & 0.61 & 0.67 & 1.13 \\
\hline & 0.63 & 2.13 & 5.52 & 1.91 & 1.12 & 4.09 & 0.70 & 1.96 & 4.45 & 1.66 & 2.00 & 4.47 \\
\hline Spain & 0.38 & 0.75 & 0.50 & 0.23 & 0.58 & 0.48 & 0.28 & 0.69 & 0.61 & 0.50 & 0.69 & 0.42 \\
\hline spall & 1.17 & 2.67 & 1.62 & 0.74 & 1.99 & 1.78 & 0.85 & 2.19 & 2.11 & 1.41 & 2.59 & 1.30 \\
\hline Swed & 0.55 & 1.07 & 1.31 & 0.92 & 0.60 & 0.80 & 0.58 & 0.59 & 1.22 & 0.83 & 1.01 & 0.62 \\
\hline sweden & 1.32 & 3.13 & 3.54 & 2.12 & 1.73 & 2.45 & 1.46 & 1.78 & 3.34 & 2.00 & 3.72 & 1.73 \\
\hline itzerland & 0.35 & 0.80 & 0.43 & 0.57 & 0.75 & 0.31 & 0.51 & 0.47 & 0.43 & 0.39 & 0.47 & 0.77 \\
\hline 200 & 1.20 & 3.17 & 1.64 & 1.89 & 3.02 & 1.29 & 1.76 & 1.78 & 1.75 & 1.30 & 1.97 & 3.29 \\
\hline UK & 0.74 & 0.82 & 0.72 & 0.80 & 0.72 & 0.67 & 0.84 & 0.77 & 0.72 & 0.68 & 0.78 & 0.73 \\
\hline On & 4.06 & 4.75 & 4.03 & 4.34 & 4.15 & 3.78 & 5.26 & 4.29 & 4.08 & 3.66 & 4.36 & 4.05 \\
\hline$\# \max$ & 1 & 6 & 4 & 5 & 2 & 4 & 3 & 2 & 6 & 1 & 5 & 5 \\
\hline ranking & 2.64 & 1.45 & 1.91 & 1.82 & 2.27 & 1.91 & 2.27 & 1.91 & 1.82 & 2.45 & 1.55 & 1.91 \\
\hline
\end{tabular}




\section{Fig. 1. Cumulative Momentum Returns: Quintile and Hedge Portfolios}

The upper graphs give cumulative total returns of the winner and loser quintiles of the earnings momentum strategy in terms of a highlighted spread while the returns of the price momentum winners and losers are added as dashed lines. The performance of an equally-weighted market portfolio is given by the solid line. The lower graphs give cumulative total returns of the price momentum strategy (dashed line) and to the earnings momentum strategy (solid line). Results are for the period from January 1988 to March 2009.
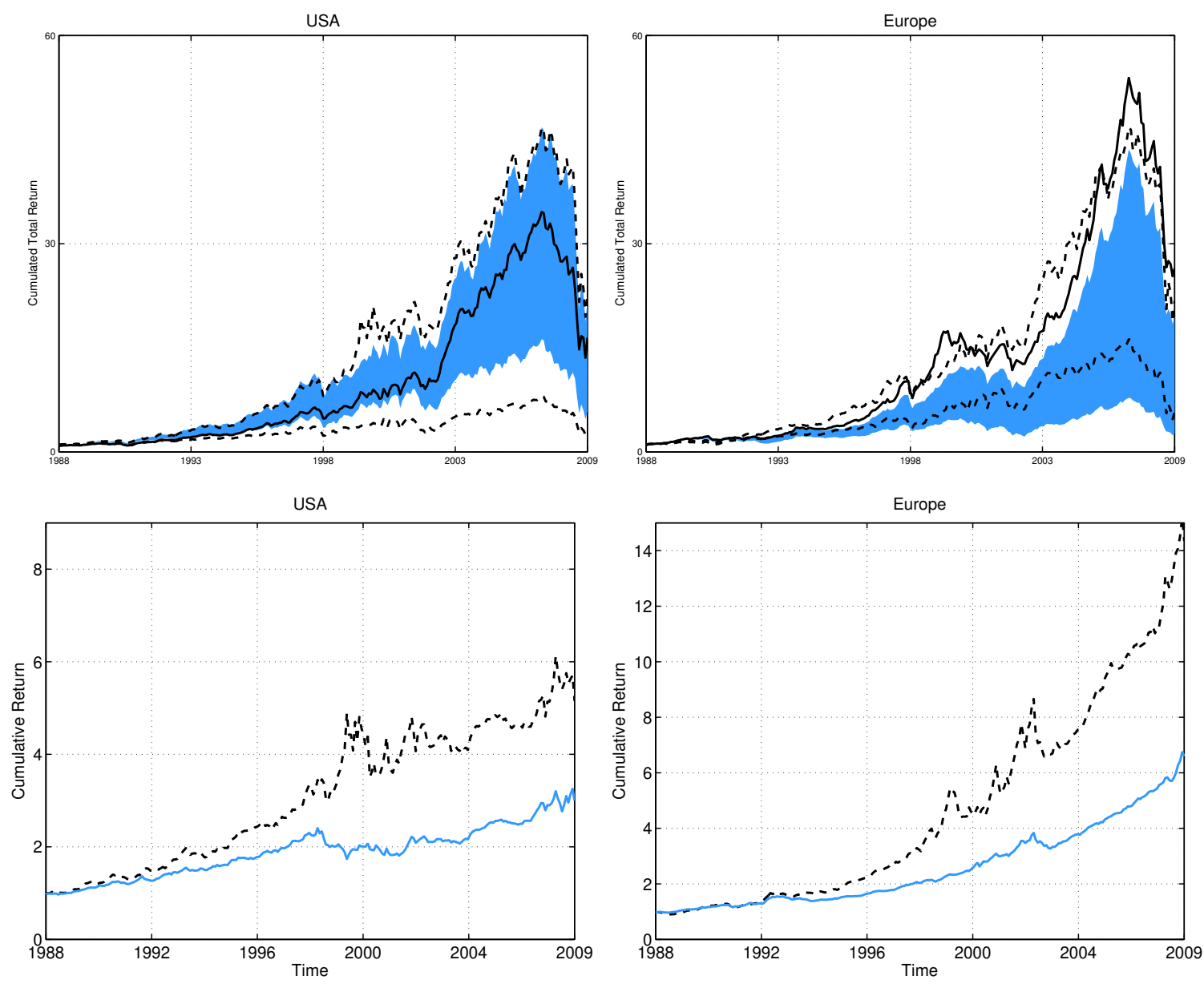


\section{Fig. 2. Momentum: Fama-French versus Four-Factor Alphas}

In the upper graphs, we plot trailing price momentum alphas arising from equations (3) and (4) using 36-month windows, thus results cover July 1990 to June 2007. Likewise, the lower graphs give trailing earnings momentum alphas arising from equations (3) and (5). The dashed line gives the Fama-French alpha and the solid line is the respective four-factor alpha.
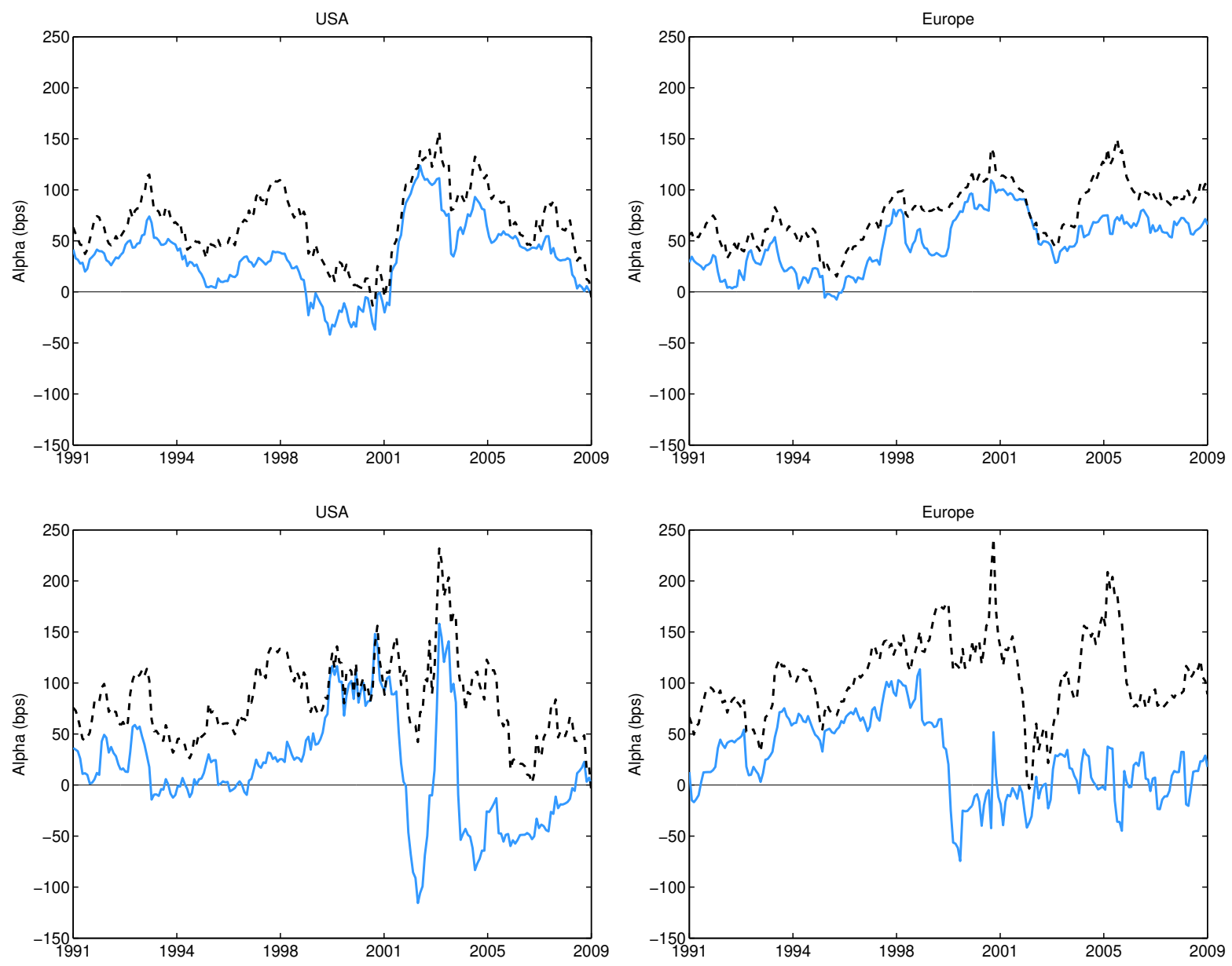